ANL - 5653

Metallurgy and Ceramics

ARGONNE NATIONAL LABORATORY

P. O, Box 299

Lemont, Illinois

DEVELOPMENT OF ULTRASONIC TECHNIQUES FOR INSPECTING EXPERIMENTAL BOILING WATER REACTOR

CAST URANIUM ALLOY CORES AND FUEL PLATES

by

W. N. Beck and W. J. McGonnagle

Metallurgy Programs 12.2.1 \& 12.2 .3

December 1957

Portions of the material in this report have appeared in the following Metallurgy Division Quarterly Reports:

ANL-5489 (17) July, Aug., Sept. 1955

ANL-5541 (18) Oct., Nov., Dec. 1955

ANL-5563 (29) Jan., Feb., Mar. 1956

Operated by The University of Chicago

under

Contract W-31-109-eng-38 


\section{DISCLAIMER}

This report was prepared as an account of work sponsored by an agency of the United States Government. Neither the United States Government nor any agency Thereof, nor any of their employees, makes any warranty, express or implied, or assumes any legal liability or responsibility for the accuracy, completeness, or usefulness of any information, apparatus, product, or process disclosed, or represents that its use would not infringe privately owned rights. Reference herein to any specific commercial product, process, or service by trade name, trademark, manufacturer, or otherwise does not necessarily constitute or imply its endorsement, recommendation, or favoring by the United States Government or any agency thereof. The views and opinions of authors expressed herein do not necessarily state or reflect those of the United States Government or any agency thereof. 


\section{DISCLAIMER}

Portions of this document may be illegible in electronic image products. Images are produced from the best available original document. 
No.

Page

LISTS OF TABLES AND FIGURES ............ 3

I ABSTRACT ..................... 5

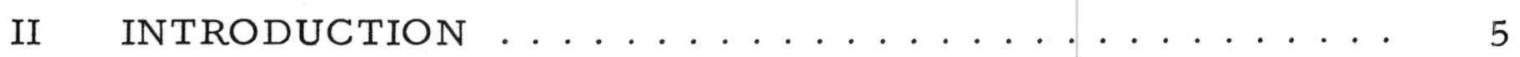

III DISCUSSION OF TEST METHOD ............ 6

IV DESCRIPTION OF EQUIPMENT ............ 7

V ULTRASONIC TEST OF URANIUM ALLOY CASTINGS . . . 13

VI ULTRASONIC TEST OF THE EXPERIMENTAL BOILING WATER FUEL PLATES . . . . . . . . . . . . . 22

VII ULTRASONIC TEST OF FUEL ELEMENTS IN SUBASSEMBLIES ........................... 26

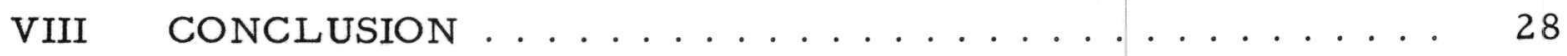

IX ACKNOWLEDGEMENT .................. 30

X REFERENCES .................... 30 


\section{LIST OF FIGURES}

No.

Title

1. 4-1/2-Foot Ultrasonic Scanner and Recording Equipment on Which the Initial Tests Were Performed

2. Ultrasonic Scanner and Recording System ... . . . . . . 8

3. The Carriage Assembly and Scanner Drive Mechanism.... 9

4. Carriage Showing the Transducer Yoke .......... 10

5. Recording Cabinet ..................... 11

6. Schematic of Modifications Made at Synchronization

Circuit of the Sperry U. R. Reflectoscope .......... 11

7. Schematic Diagram of the Recorder Driver ... . . . . . 12

8. Helix Recorder Designed for Use with Electrosensitive Paper ........................ 14

9. Recording of Artificial Defect Indicating Resolution of Equipment ...................... 14

10. Recordings of Casting K-86-4 Made at Different Sensitivity Levels. The Marked Areas Were Places where Casting Was Sectioned and Inspected

11. Macrograph of Section K-86-4-2 Revealing Type of Inclusion Detected . . . . . . . . . . . . . . 16

12. Macrograph of Section K-86-4-13, Comparison Photograph of Casting Showing the Absence of Inclusions . . . . . . . . . . . . . . 17

13. Bands of Large Inclusions Detected in Casting K54-8B .... 18

14. Recording of Casting before and after Heat Treatment Showing the Effect of Change of Grain Size . . . . . . .

15. Composite Recordings of Five Castings of Billet No. 7 Showing Shrink Pattern ................. 


\section{LIST OF FIGURES}

No.

Title

Page

16. Composite Recordings of Five Castings of Billet No. 9 Showing Shrink Pattern ................ 21

17. Recording of Casting K76-10 Indicating Area of Shrink . . . 22

18. Cut-away Section of Casting K76-10 Showing Shrink Area Recorded in Figure $17 \ldots \ldots . \ldots . \ldots 23$

19. Recording of Known Defect Plate Used to Determine Resolution of Equipment ................ 24

20. Photograph of Etched-Out Inclusion in Fuel Plate Which was Detected Ultrasonically .............. 25

21. Core to Clad Nonbonded Area Detected in Fuel Plate .... 27

22. Nonbond Area in the Zircaloy-Zircaloy Inner Face . . . . 27

23. EBWR Subassembly and Ultrasonic Probe Designed to Test Fuel Plates while in Subassembly . . . . . . . . . 29

24. Photograph of Probe Inserted in Subassembly. . . . . . . 29 


\title{
DEVELOPMENT OF ULTRASONIC TECHNIQUES FOR INSPECTING EXPERIMENTAL BOILING WATER REACTOR \\ CAST URANIUM ALLOY CORES AND FUEL PLATES
}

by

\author{
W. N. Beck and W. J. McGonnagle
}

I. ABSTRACT

An ultrasonic test technique was developed for the inspection of fuel plates, uranium alloy cores and fuel plates in subassemblies for the Experimental Boiling Water Reactor (EBWR). For these tests a special scanner was designed and fabricated. The equipment could serve as a researchtool as well as being used for inspecting numerous items of diversified lengths and shapes. A transmission technique was used at an ultrasonic frequency of 5 megacycles. The mechanical motion of the inspecting transducers was synchronized to a helix recorder so as to provide a permanent two-dimensional recording on electrosensitive paper. It was possible to detect piping, shrink, porosity, inclusions and microinclusions in the uranium alloy castings. In the completed fuel plates, a nonbond area of $1 / 8$ of an inch in diameter could be located. With the construction of a special two-arm probe, fuel plates installed in subassemblies were successfully tested by a trans-

mission technique.

\section{INTRODUCTION}

The specifications which are imposed on the construction of experimental power reactors are designed to exercise stringent controls on all materials which are utilized in the fabrication. The aim of this policy is the minimization of the possibility of malfunction or failure of component parts. The strictness of the specifications stems mainly from the fact that accessibility of components is limited and, once a complete installation is made within a closed system, removal of any one part due to failure reduces the reliability factor of the whole system. This problem is magnified when consideration is given to the possibility of radioactive contamination which would involve decontamination of the system before repairs could be effected.

In this respect nondestructive testing of the reactor components offers a degree of assurance that each item, part or section tested is free from known defects or flaws which might be detrimental to the operation of the reactor. 
This report covers a portion of tests which were developed to ins pect fuel material. It is limited to the field of ultrasonic inspection and its specific application in the testing of reactor components of the Experimental Boiling Water Reactor.

\section{DISCUSSION OF TEST METHOD}

The application of an ultrasonic technique to the problem of detecting flaws has been previously performed on various materials as well as fuel elements.(1), (2), (3) The test method is unique in the determination of certain types of metallurgical defects not readily apparent by other methods. Flaws such as lack of bonding, inclusions, cracks and voids are examples of defects which can be readily detected by ultrasonics.

In applying a transmission technique, two separate transducers are used. One transmits ultrasonic energy while the other performs the function of a receiver. The specimen which is to be tested is placed between both transducers and the attenuation of the transmitted energy through the test specimen can be detected. In this technique, the selection of frequency and size of the transmitted beam are of prime consideration. A more linear propagation of an ultrasonic beam is attained at high frequencies. (4) The cross-sectional area of the transmitted beam has a direct bearing on the size of the flaw that can be detected. By masking the transmitting transducer the size of the transmitted beam can be controlled. A mask is acoustic absorbent material which covers the transducer. A hole drilled in this mask provides a specific beam aperture. The selection of mask opening is dependent on such factors as frequency, available ultrasonic energy, and types and sizes of material being tested. Consequently, the determination of a minimum mask opening is usually obtained by succes sive tests with various apertures. An ultrasonic frequency of 5 megacycles was selected for these tests.

At various stages in the manufacturing process for components of the Experimental Boiling Water Reactor a nondestructive test was requested for the purpose of quality control. The as-cast uranium cores, the completed fuel plates and a few fuel plates installed in subassemblies were tested ultrasonically. In order to perform the tests, a scanner was designed and test techniques were developed. A detailed description of the equipment and test method applied to each test item is included in the subsequent sections. 


\section{DESCRIPTION OF EQUIPMENT}

The initial tests on the core castings as well as the fuel elements were made on an existing $4 \frac{1}{2}$-foot scanner, seen in Figure 1. In order to meet the requirements of an accelerated production schedule a larger, mobile $10 \frac{1}{2}$-foot scanner was designed and fabricated.(5) This unit incorporated features which would make it possible to process an increased number of items of diversified shapes and lengths.

The complete scanner as seen in Figure 2, constitutes two separate units, which are, namely, tank assembly and recording system.

The tank assembly is a welded angle iron truss frame work measur ing 11 feet $\times 3 \frac{1}{2}$ feet $\times 1 \frac{3}{4}$ feet. Cross members about the midsection support a roller assembly on which the tank proper is mounted. The use of the roller facilitates repositioning of the tank or complete removal. The tank itself is 10 feet long, 14 inches wide and 12 inches deep. Constructed of $1 / 4$-inch welded steel, it is spray-coated with white Koroseal. This coating prevents the tank from corroding and also serves as an excellent acoustic absorber. The two drive motors, filtering system and relay panel are located on a platform below the roller assembly. The drive motor $\mathrm{s}$ are 1/4-hp, 0-35 $\mathrm{rpm}$ variable transmission units. The linkage between the drives and the equipment consists of $1 / 4$-inch chains which are kept in tension by chain tighteners and adjustable gears. One motor operates the transducer carriage. The other is coupled to a shaft and pulley located at one end of the tank. This drive joins a special fixture located in the tank which is used in the inspection of cylindrical test specimens. The filtering system consists of a 200-gph centrifugal pump and filter which are connected in series, with two openings at the lower extremities of the tank. This permits a filtering action, removal or filling of the tank. The ultrasonic couplant used in the tank is ordinary tap water. The relay panel provides the electrical controls for the drive motor and reversing limit switches for the carriage.

Over the tank there is located a carriage assembly which is free to traverse the length of the scanner. Figure 3 shows the scanner with the metal side plates removed. The assembly is guided by rails for linearity of direction as well as elevation. This unit is chain driven by one of the variable speed motors and with the existing gear ratio the linear speed may be varied from 0 to 16 inches per minute. This carriage carries the trans ducers and motor which provides an up and down motion. By means of a yoke assembly, Figure 4, two matched waterproof crystals are held rigidly in a preset position. One crystal is the transmitter while the other is the receiver. The crystal yoke assembly is supported by a vertical shaft which is coupled to a motor and chain drive. This mechanism provides the yoke with a vertical oscillatory motion, the amplitude of which may be varied from 1 inch to $7 \frac{1}{2}$ inches. The composite motion of the vertical 


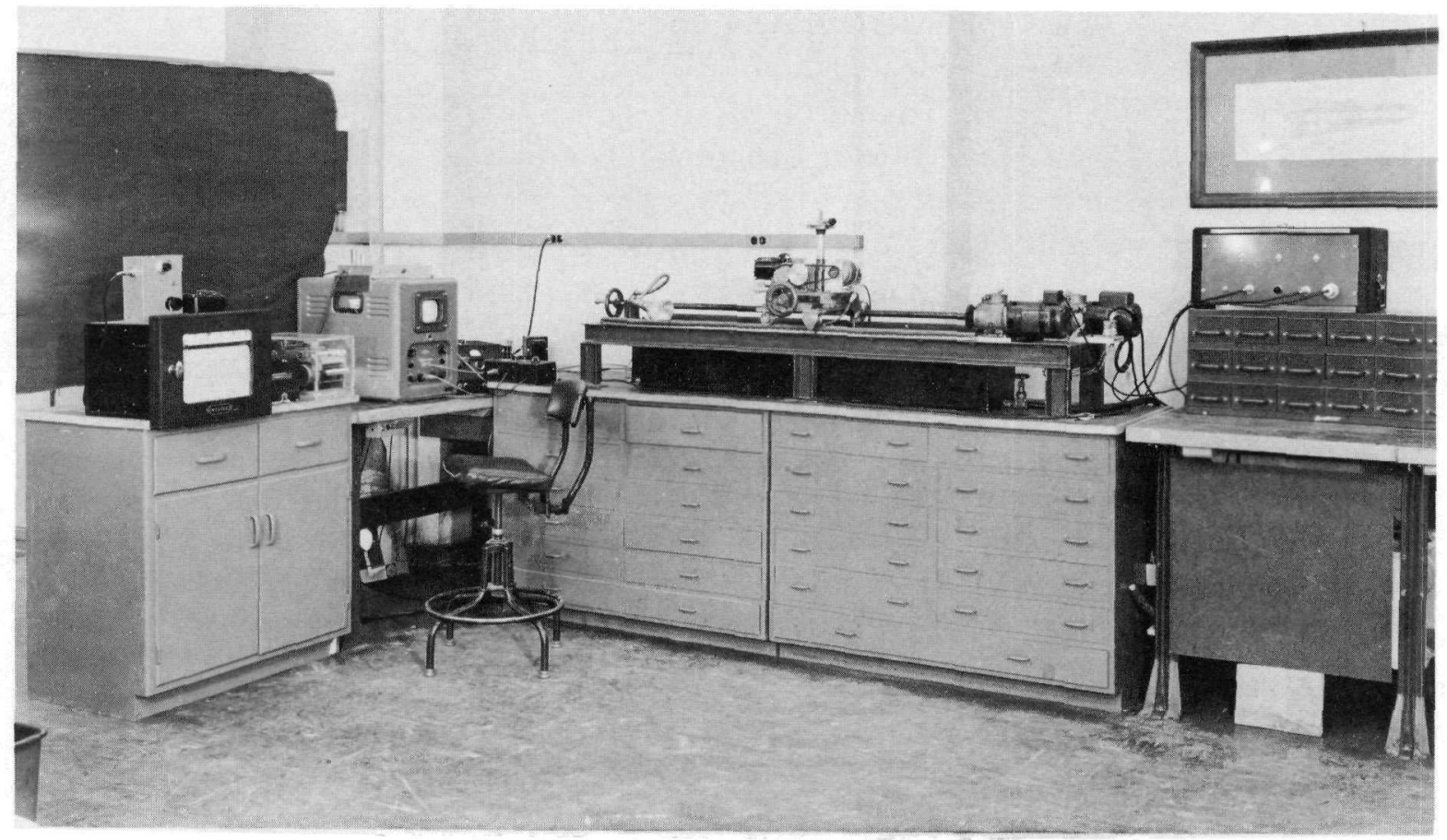

Figure 1. $4 \frac{1}{2}$-Foot Ultrasonic Scanner and Recording Equipment on which the initial tests were performed.

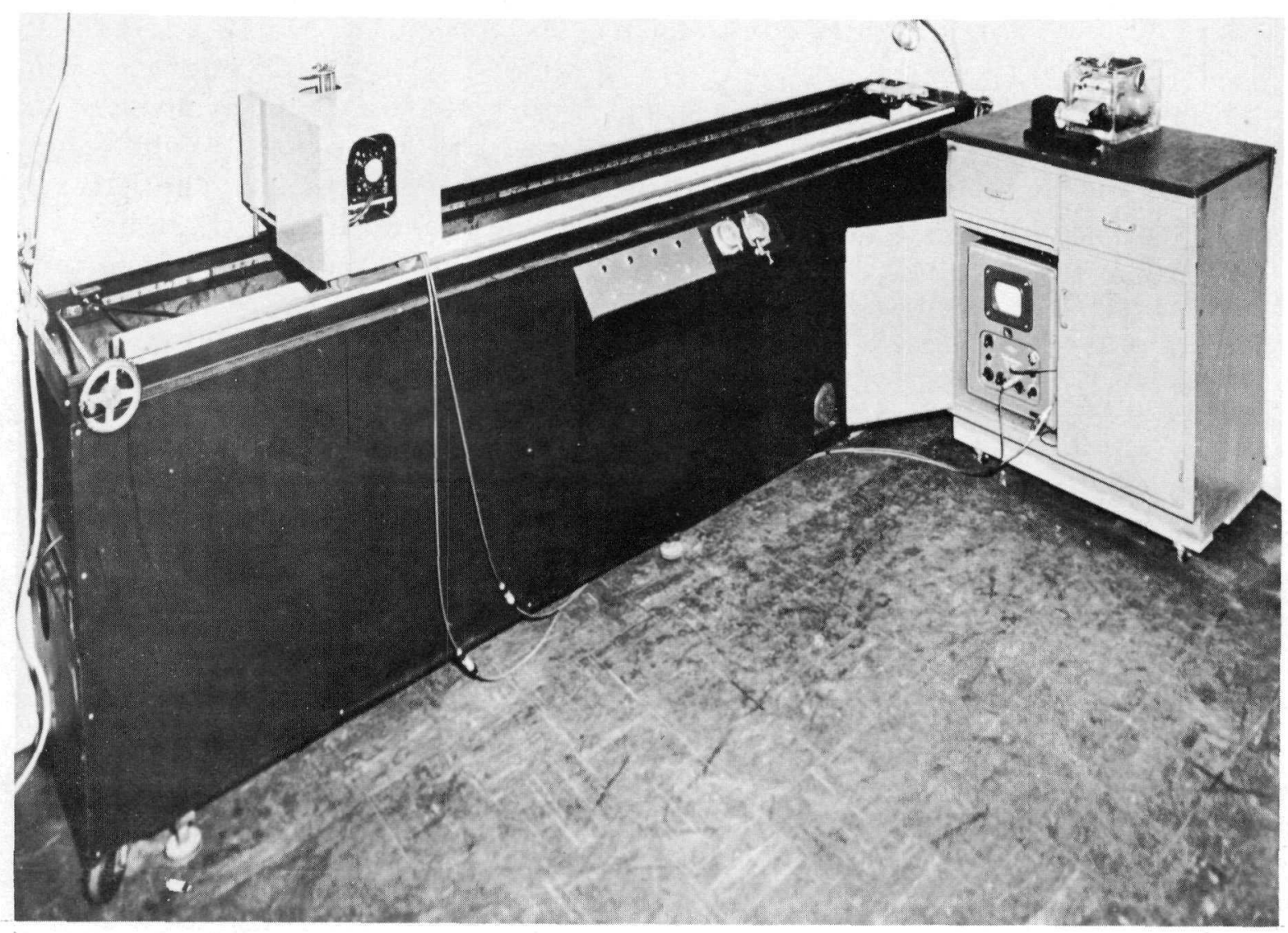

Figure 2. Ultrasonic Scanner and Recording System. 
displacement, together wi th the horizontal drive, causes the transducer to describe a sharp "saw tooth." In this manner a flat surface may be inspected in width as well as length.

The shaft which holds the transducers has been provided with micrometric angle adjustment so that the relative position of the crystals may be changed with respect to the specimen which is being inspected. This adjustment can be seen at the top of the center shaft in Figure 4.

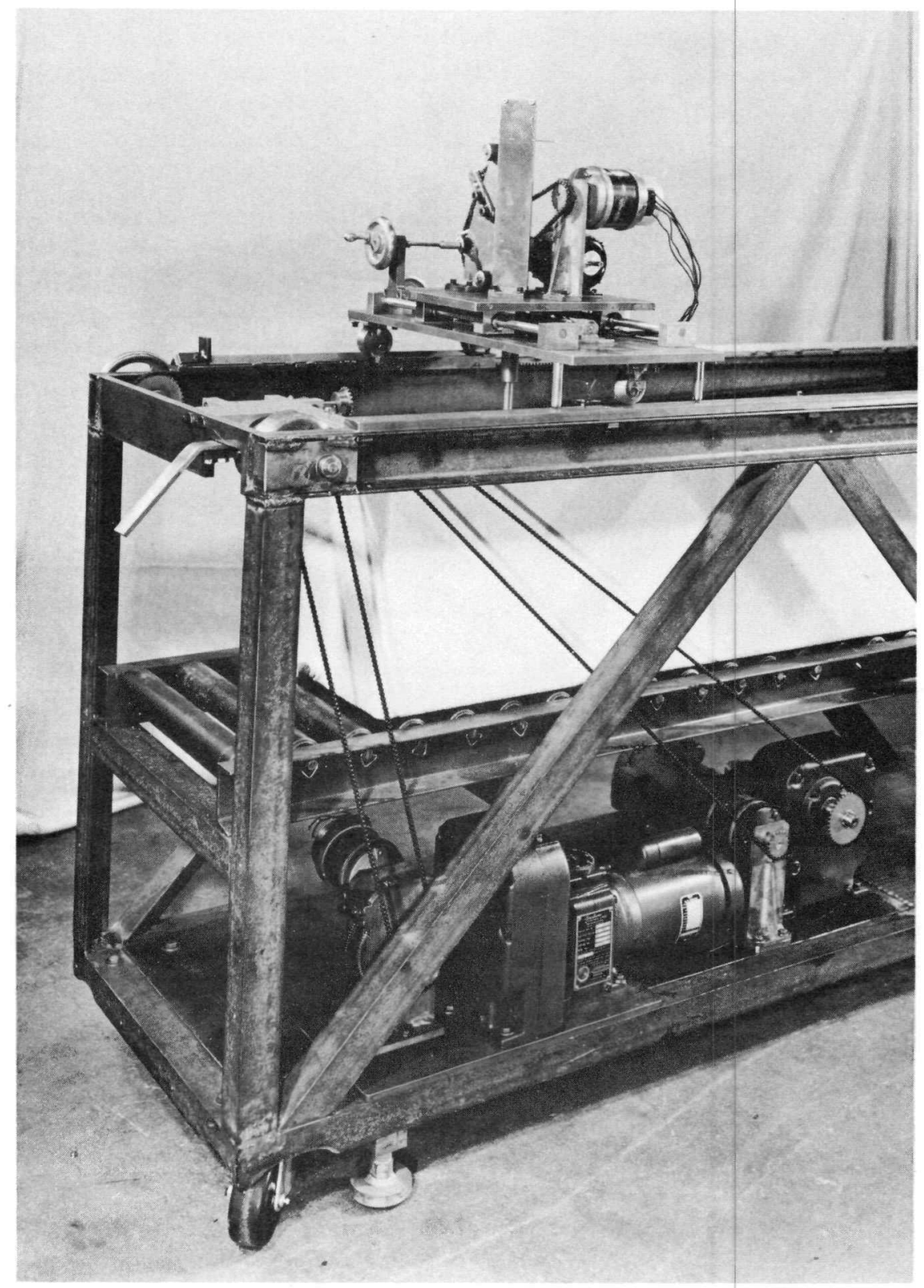

Figure 3. The Carriage Assembly and Scanner Drive Mechanism 


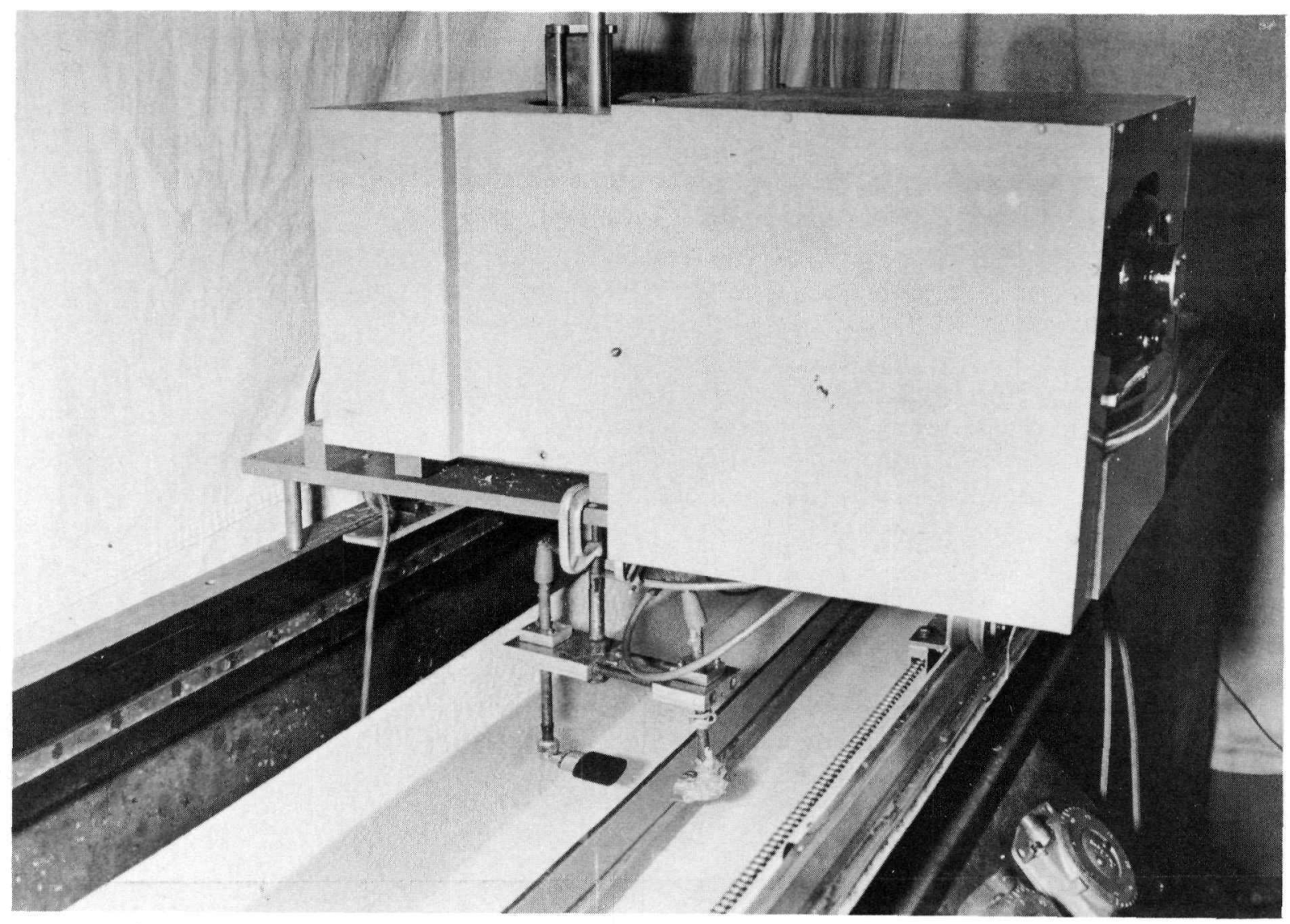

Figure 4. Carriage Assembly Showing the Transducer Yoke. The test item seen in the Tank is an EBWR flat type fuel element.

If a cylindrical element is to be inspected, it is mounted horizontally in the tank in a special fixture which holds the piece by the ends. The transducer carriage then transports the transducers, locked at a fixed elevation, past the specimen as it is being rotated by one of the variable speed drives. The linkage to the fixture holding the cylindrical specimen is made by attaching the chain and sprocket drive located at the end of the scanner.

The cabinet, Figure 5, houses the electronic and recording equipment. The ultrasonic driver is a Sperry UR Reflectoscope which has been modified for two-crystal operation. This particular unit can operate at the following frequencies: $0.5,1.0,2.25$, and 5 megacycles. The basic pulse repetition rate was made variable from 60 to $240 \mathrm{cps}$ in order to obtain satisfactory recording resolution at high scanning speeds. The modification made to the synchronization circuit of the Reflectoscope is shown in Figure 6. 


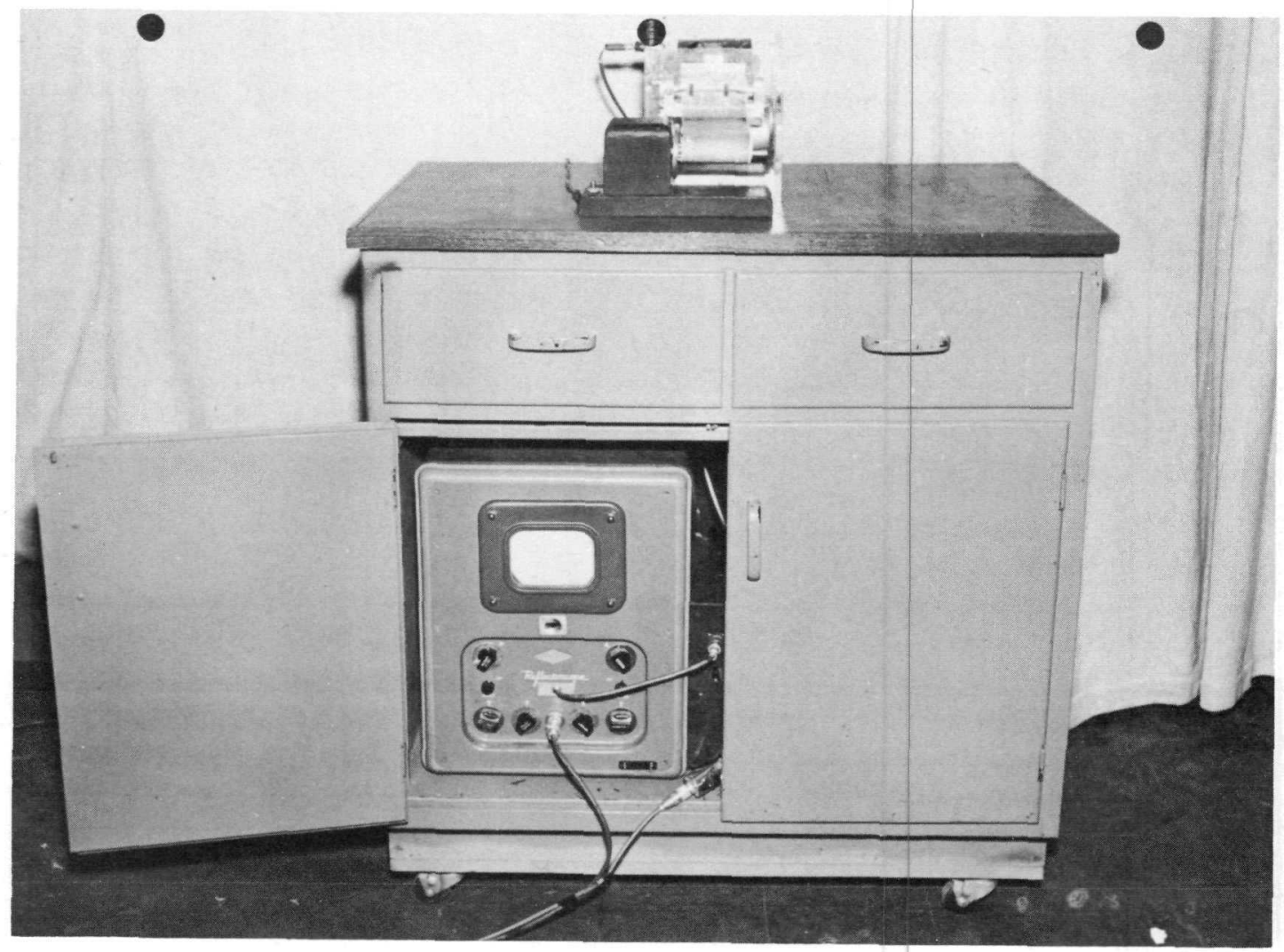

Figure 5. Recording Cabinet

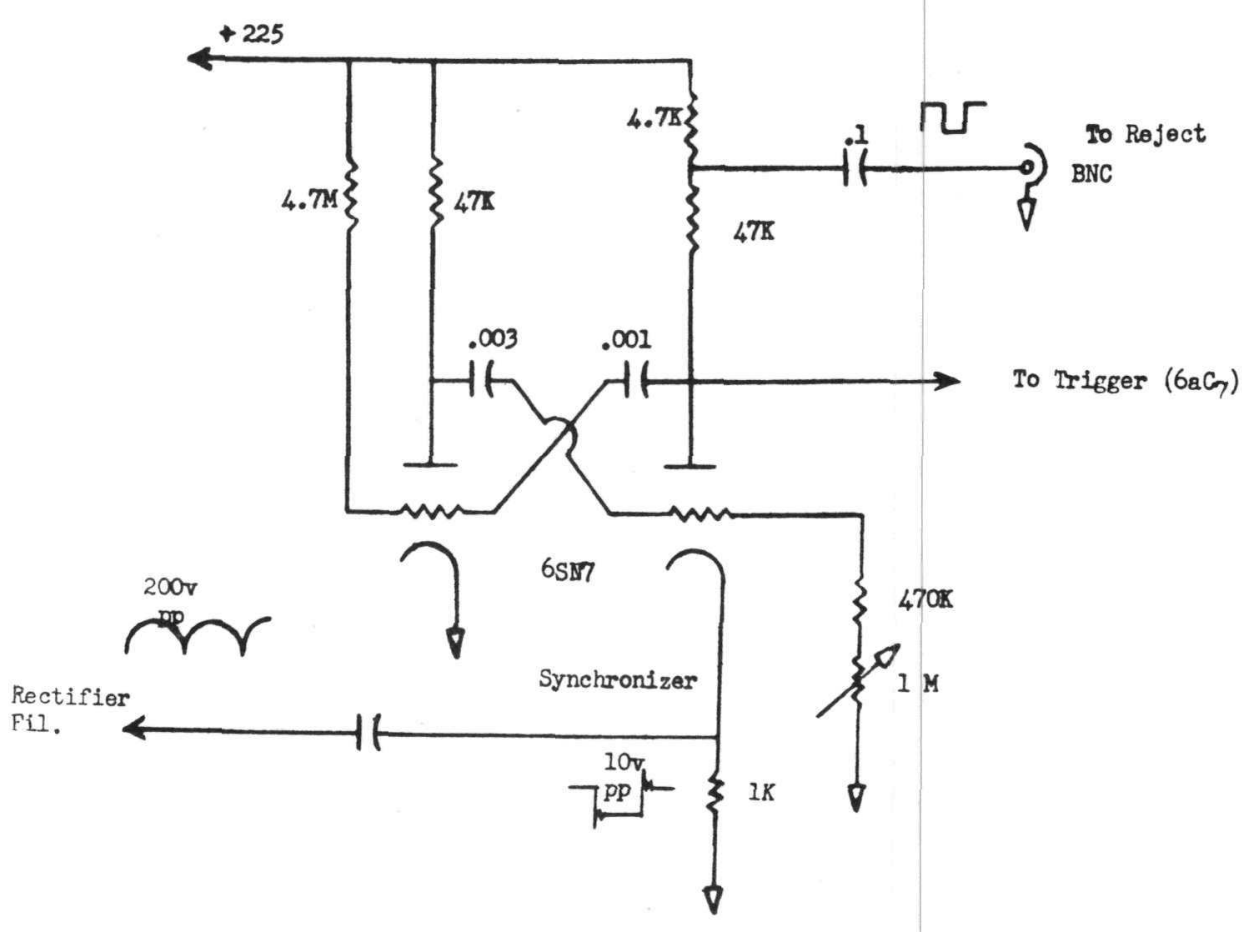

Figure 6. Schematic of modifications made to synchronization circuit of the Sperry UR Reflectoscope. 
The recording circuitry, Figure 7, converts the amplified pulse from the receiving crystal to a square wave rectified, 26-volt signal which is applied to the writing electrode of the helix recorder. Since the input to this circuit was connected to the vertical deflection plates of the cathode ray tube it became necessary to provide a gate which would reject the initial pulse which appears on the scope. This initial pulse appears on the horizontal sweep line at the instant the synchronizer in the Reflectoscope triggers the high-voltage pulse. The pulse is of a magnitude which would trip the writing tubes making identification of the received pulse impossible. The gate has been made adjustable so that in addition to eliminating the initial pulse it can be set to reject all spurious signals other than the received impulse. Other provisions in the circuit permit control of output current (writing contrast), pulse length (writing time) and trigger leve1 (voltage at which writing tube will conduct). In the application of an ultrasonic transmission technique, the loss of energy detected by the receiving transducer provides the information as to nature and characteristics of the material through which the energy was transmitted. The amplitude of the received impulse therefore is discriminated, gated and recorded.

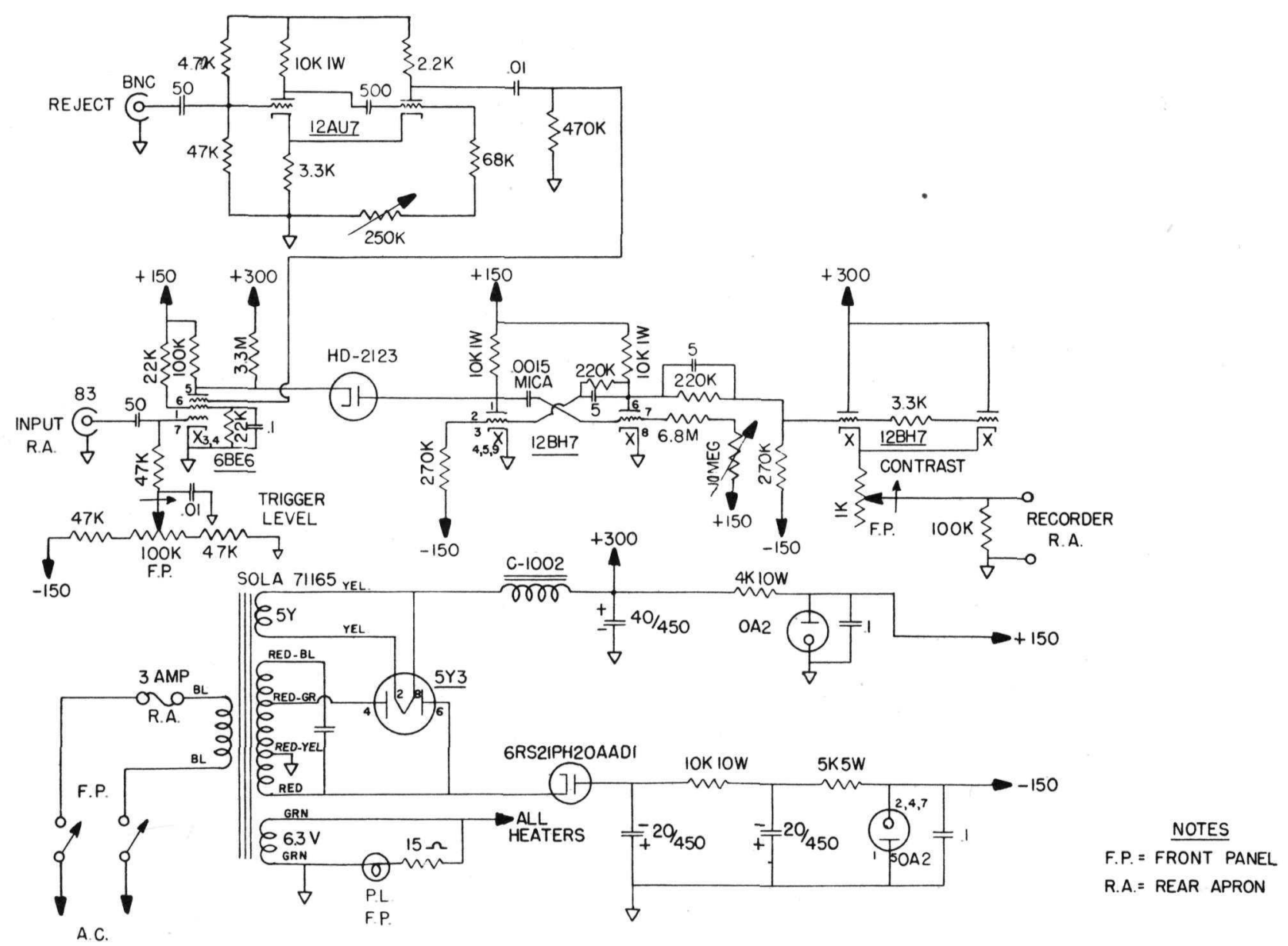

Figure 7. Schematic Diagram of the Recorder Driver. 
The helix recorder, Figure 8 , is a self-contained unit powered by two synchronous motors. One motor, which drives the paper feed, is coupled to the translation motion of the transducer carriage. It is matched so that the travel of the carriage will cause the recorder to displace an equal length of recording paper. By the use of limit switches and relays the synchronous motor is made to operate in only one direction, even though the carriage has reversed its direction. The other synchronous motor, which rotates the helix, is coupled to the transducer yoke motor on the transducer carriage. It is preset so that the half-cycle excursion of the transducer (i. $e_{\text {. }}$, distance traveled in the vertical plane) produces one revolution of the helix. The writing pen is a flat, stainless steel knife which bears against the helix, making a one-point contact at all times. At each up-stroke of the transducers the point of contact between the writing pen and helix sweeps completely across the recording paper. Therefore the recorded trace bears the exact dimensions of the item which is being inspected.

The recording is made on electrosensitive paper which produces a chemical discoloration as a direct function of the applied current. This paper must be maintained moist and is kept in a humidor which is positioned directly behind the helix guide roller. Two commercially available electrosensitive papers have been used with the recorder. One is Alfax, which produces a brown-on-white discoloration; the other is Mufax, which produces a black discoloration on white. These papers provide a permanent trace without additional fixing.

A microswitch located on the carriage is connected in series with the external circuit leading to a writing pen. This switch is synchronized so that writing occurs only when the transducers are on an "up-stroke." It was necessary to do this since the helix continues to revolve in the same direction even though the transducers have reversed their direction.

As a means of demonstrating the resolution of the equipment with this mask opening, an artificial defect in the form of the letters "ANL" was cut from a stencil. The recording of this defect can be seen in Figure 9. The top letters represent the original and the bottom, the actual recording.

\section{ULTRASONIC TESTS OF URANIUM ALLOY CASTINGS}

\section{Description of Core}

The as-cast alloy core used in the manufacture of EBWR fuel plates measured approximately 11 inches long, 4 inches wide and 1 inch thick. Depending upon the particular mold used, the ends of the castings were either flat, one end with a $90^{\circ}$ included angle taper or both ends tapered. (6) 


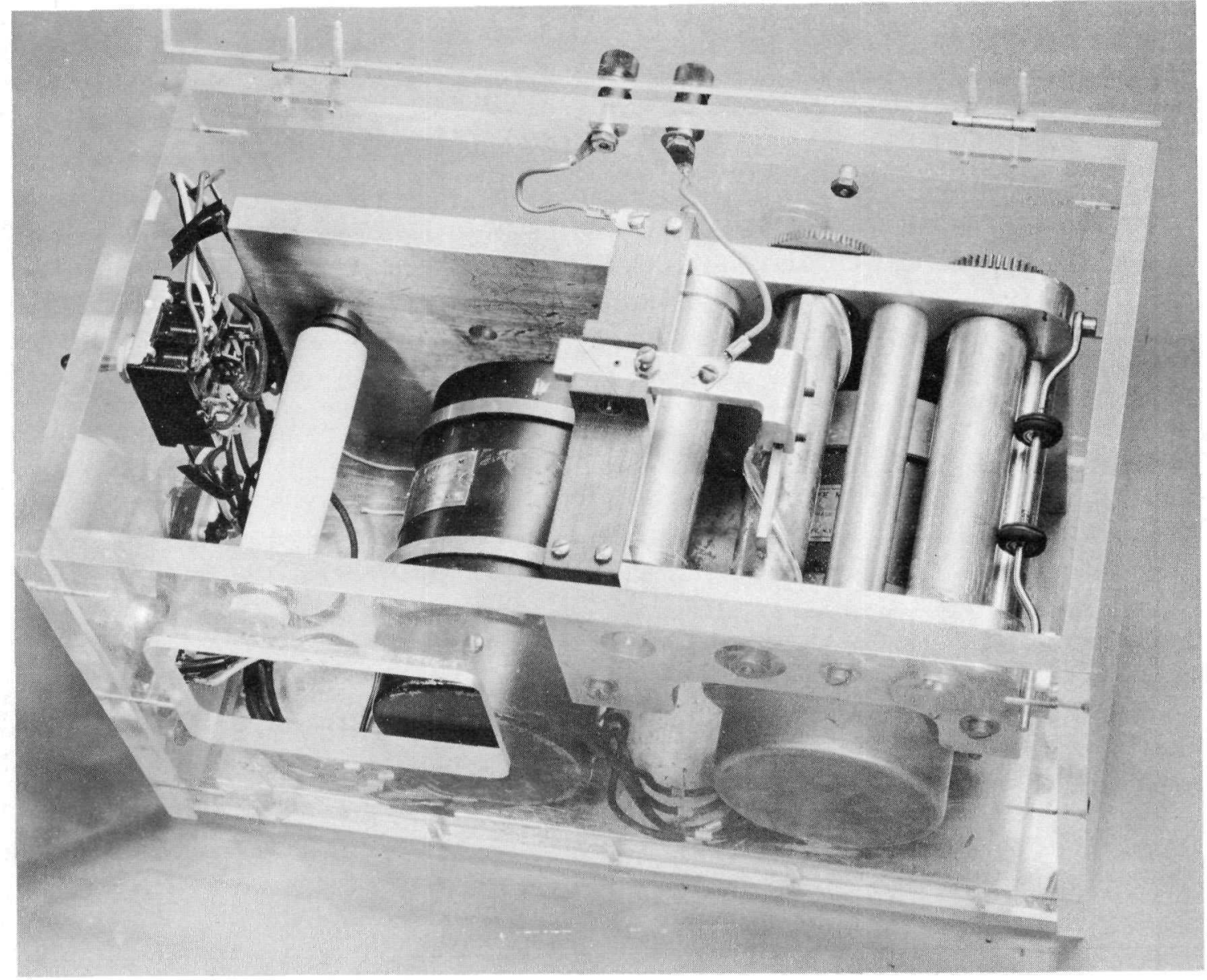

Figure 8. Helix Recorder Designed for Use with Electrosensitive Paper.

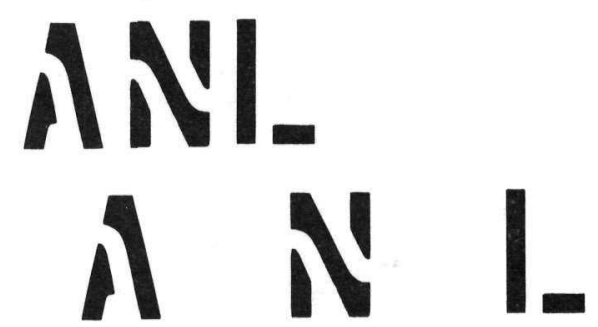

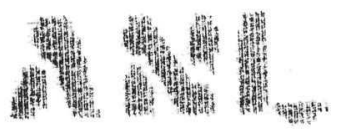

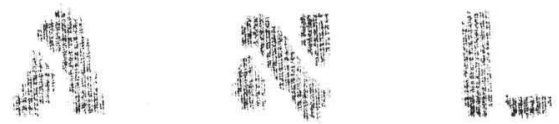

Figure 9. Recording of Artificial Defect Indicating Resolution of Equipment. 
The surfaces were relatively smooth with the exception of occasional pits or ridges, which were introduced by irregularities of the mold faces. The composition of the core was $\mathrm{U}-5 \mathrm{w} / \mathrm{o} \mathrm{Zr}-1.5 \mathrm{w} / \mathrm{o} \mathrm{Nb}$. The cores were cast in two different thicknesses; the variation, however, was not of a magnitude which necessitated modification to the test method.

Test Procedure

The dimensions of the tank of the scanner were such that it would accomodate eight castings placed end to end. They were supported on a pedestal aluminum rail which elevated the castings $2 \frac{1}{2}$ inches above the bottom of the tank. The transducer yoke assembly straddled the casting and was positioned so that the transmitted ultrasonic beam maintained an angle of $90^{\circ} \pm 1 / 2^{\circ}$ relative to the surface of the casting. The vertical travel of the yoke was set so that the scanning beam would traverse the full width dimension of the casting.

An ultrasonic frequency of $5 \mathrm{Mc}$ was a selection which was experimentally determined to be applicable in the determination of structure variations in this type of material. A minimum mask opening of $5 / 64-$ inch diameter was maintained.

The concept of the initial tests was to establish a correlation between the ultrasonic recording and the metallurgical structure of the casting. In order to perform this, several recordings were made of one casting at various recording sensitivity levels. Figure 10 is a photograph of three recordings of the same casting. This particular casting was poured in a vertical mold. The lettering at the right hand side of the traces serves to identify what would normally be referred to as the top of the casting. The dark area of the recorded trace, which was formed by parallel mark lines, indicates that ultrasonic transmission through the casting was possible at this particular sensitivity level. Conversely, the white or blank area indicates that the transmitted energy was attenuated to such a degree that it fell below the recording sensitivity level.

This casting was then sectioned and the selected areas (shown in Trace A) were polished, etched and inspected. A $250 \mathrm{X}$ magnification of the sections revealed a contrasting lattice and the presence of inclusions. Figure 11 corresponds to the white-area section which is labeled K86-4-2, which reveals the nature of the inclusions. A comparison section K86-4-13, shown in Figure 12 at the same magnification, was found to be free from this particular formation. This section had been cut from an area in the casting which represented "good" ultrasonic transmission. Although this inclusion could be detected at this particular sensitivity level and at this frequency, its presence was not considered detrimental to the integrity or usefulness of the casting; consequently, subsequent tests were conducted at sensitivity levels above which this type of structure would not be detected. 

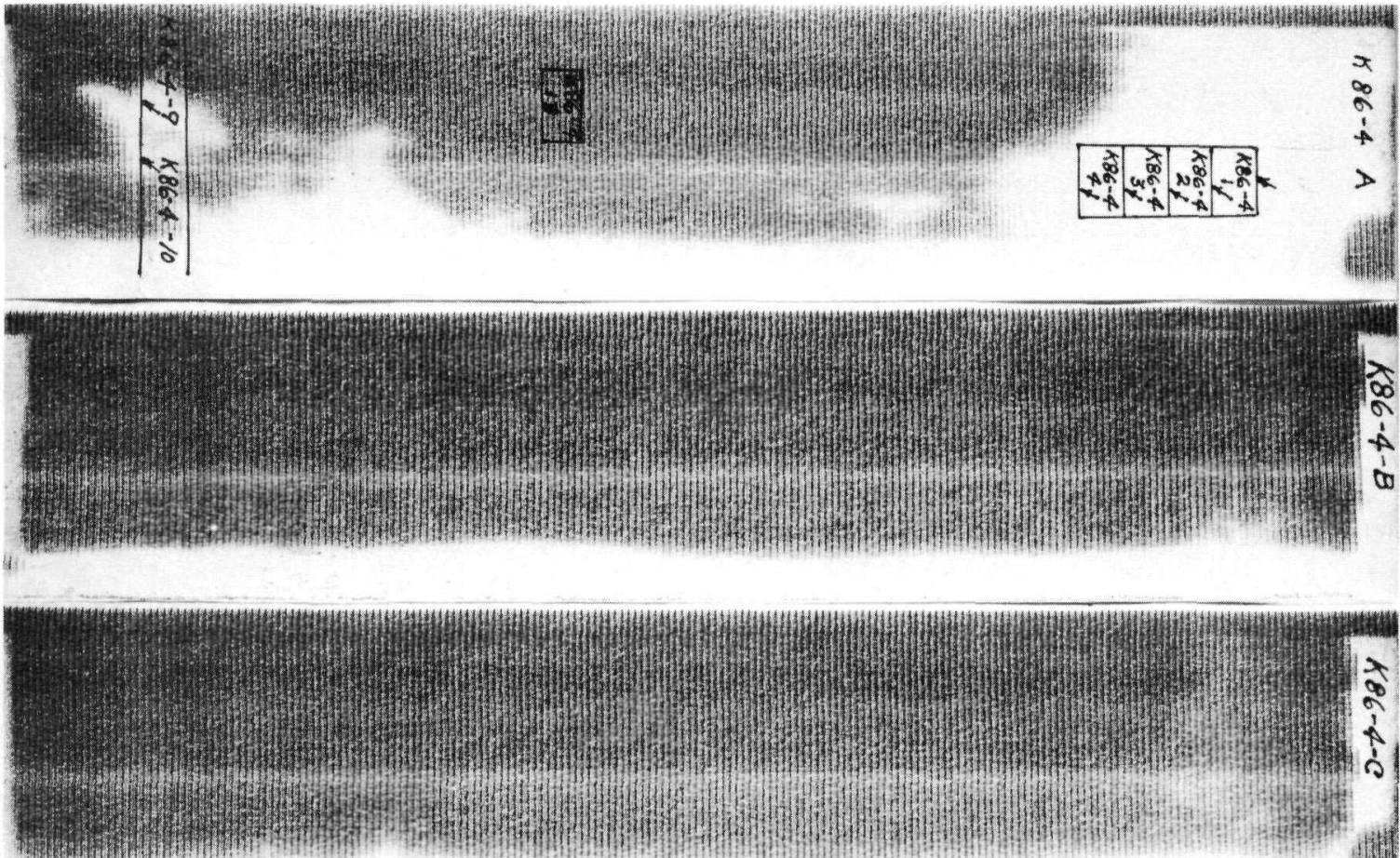

Macro \#18399

Figure 10. Recordings of casting K86-4 made at different sensitivity levels. The marked areas were places where casting was sectioned and inspected.

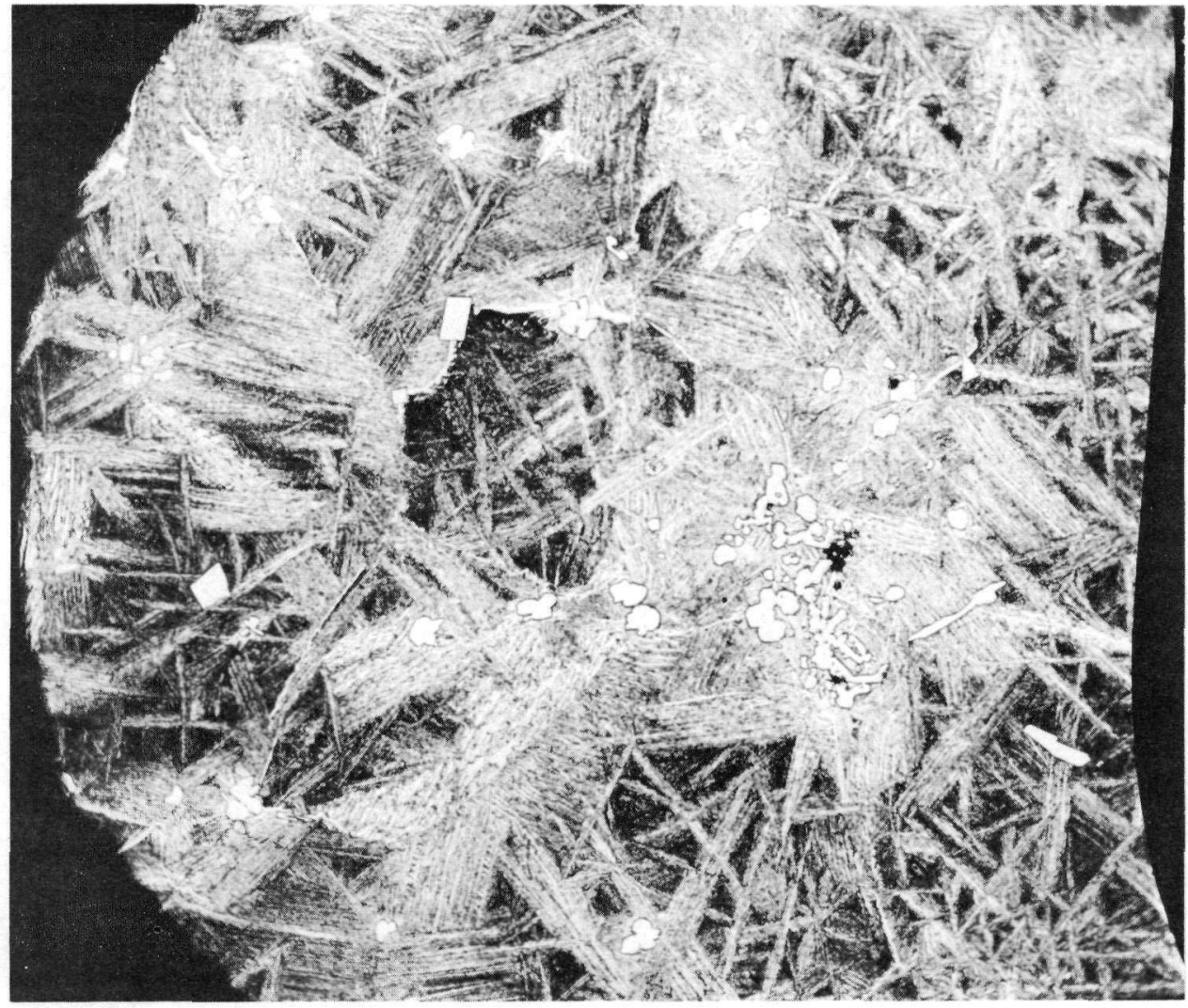

Figure 11. Macrograph of Section K86-4-2 revealing type of inclusion detected. 


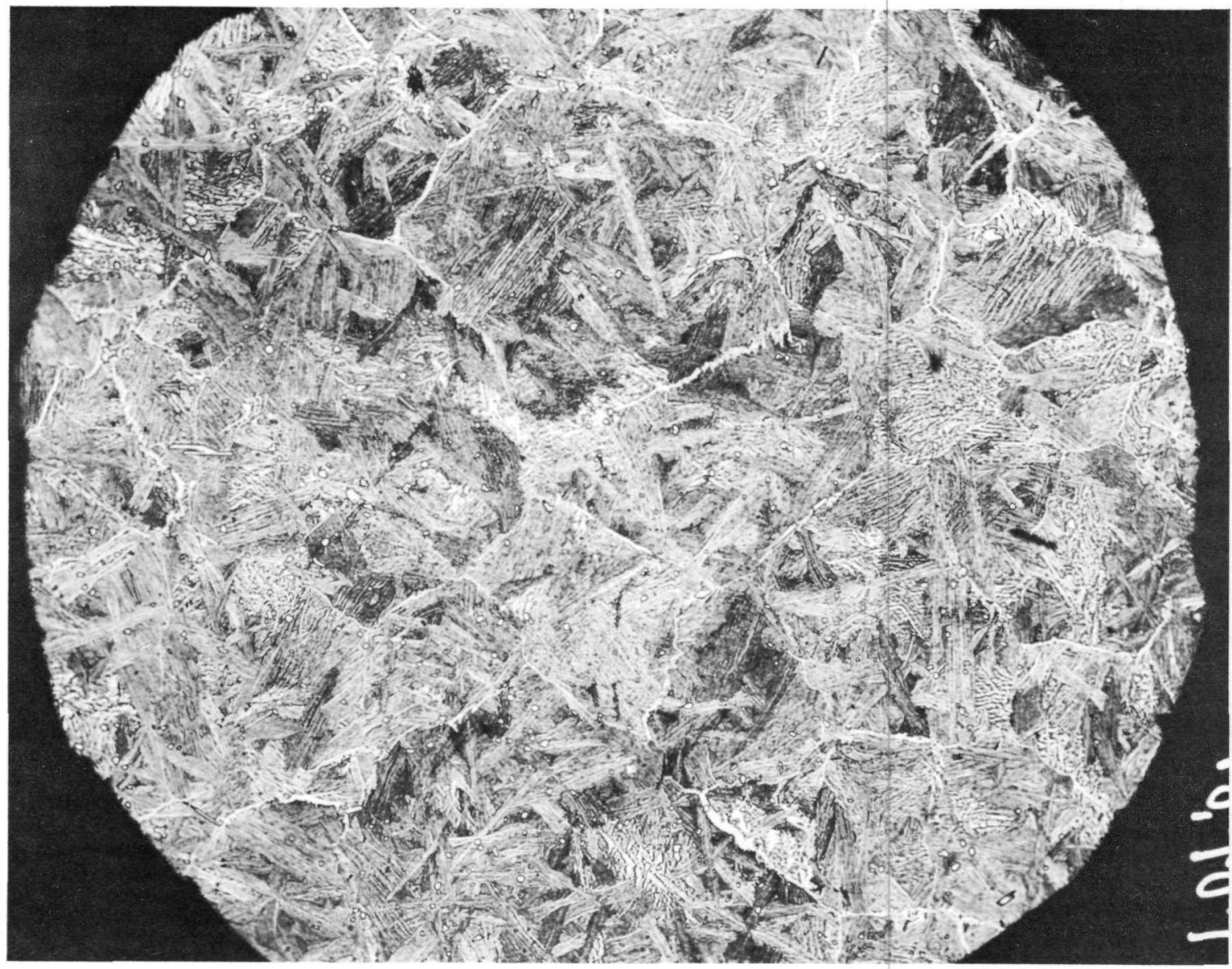

Macro \#18407

$250 \mathrm{X}$

Figure 12. Macrograph of section K86-4-13. Comparison photograph of casting showing the absence of inclusion.

In order to establish a normal or standard which would insure that deviations in the electronic circuitry would not introduce a variable, a casting and its recording was retained. This casting was periodically rerun and the recording checked against the standard trace. Any deviation in sensitivity would be noted in the recording and adjustments were made until the trace was the exact duplicate of the standard.

In subsequent tests another defect area was found and recorded by the equipment. Destructive tests revealed layers of inclusions which were much larger than those previously observed. The bank of inclusions appeared most generally in cores which had been cast from virgin stock. A representative $20 \mathrm{X}$ photograph of this defect can be seen in Figure 13. Corrective measures were exercised by the foundry group, eliminating this defect. 


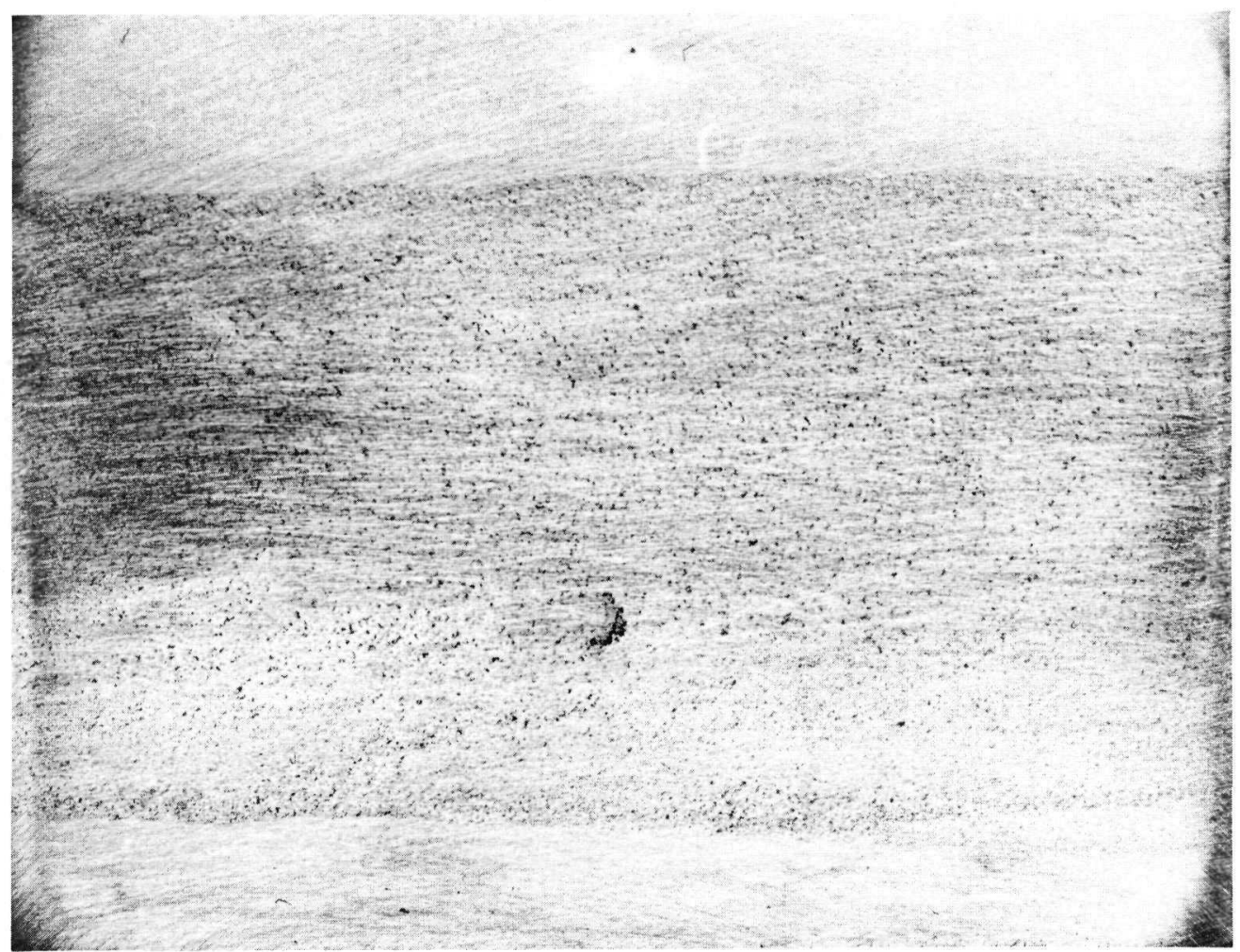

Macro \#18082

$20 \mathrm{X}$

Figure 13. Bands of large inclusions detected in casting $\mathrm{K}-54-8 \mathrm{~B}$.

At this particular sensitivity level an occasional casting was tested which indicated that the transmitted ultrasonic energy had been attenuated below the preselected minimum recording gate. This was shown by a spotted or completely blank recorded trace. A review of the manufacturing technique revealed a deviation from the established pouring temperature, cooling method or both. This deviation from regular procedure indicated the possibility of a change in the grain structure of the core.(7) In order to verify the assumption, the se cores were subjected to a 30 -minute salt bath heat test at $850^{\circ} \mathrm{C}$. The subsequent ultrasonic test, repeated under identical conditions, revealed a change in attenuation of the ultrasonic energy. An example of this can be seen in Figure 14. Which is two recorded traces of casting $\mathrm{K} 75-2$. The top trace was made before the core was heat treated. The bottom trace of the same casting, under identical conditions, was made of the core after the heat treatment. An evaluation was made on effects of this structural change and it was determined that the characteristic was not detrimental; consequently the sensitivity of the equipment was changed and a new standard was established. 


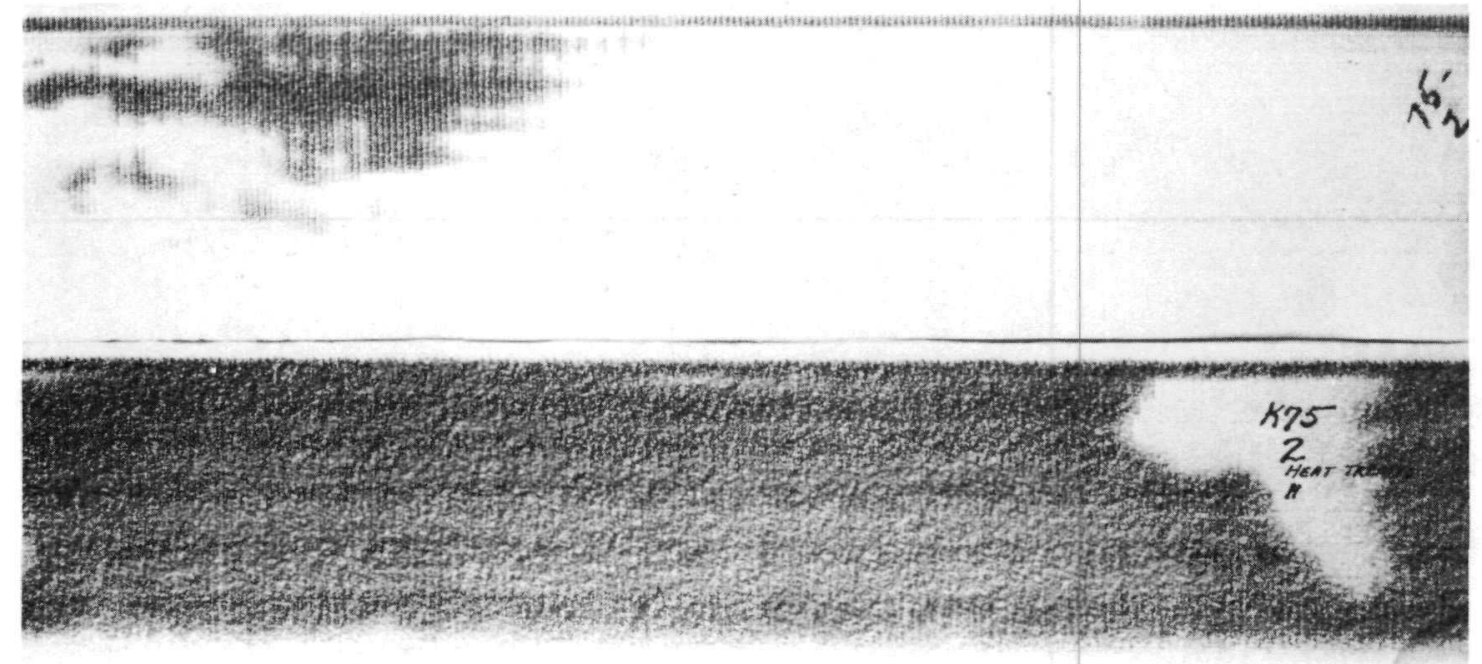

Macro \#18397

Reduced 4 times

Figure 14. Recording of casting before and after heat treatment, showing the effect of change of grain size. The top trace was made before heat treatment. The bottom one is the same casting after heat treatment.

Throughout the development program, the foundry group utilized various shapes of molds as means of arriving at a casting technique which would be suitable for production. One mold was designed such that a large flat billet could be cast from which five cores were obtained. Each core was tested ultrasonically. When the tracings of all five cores were placed in order, an interesting, continuous pattern could be observed. Figures 15 and 16 are typical examples of recordings made on 5 core billets. The designation number on the right hand side of the trace bearing a last digit of (1) identified the core cast from the top of the billet. The flaw was visually identified as piping and porosity. The progression could be followed from the top to bottom of each core throughout the length of the billet. This particular type of mold was abandoned in preference to one where each core was cast separately.

The nondestructive tests of the castings accompanied the development of the casting technique. Every core was tested and each test was compared and evaluated against previous results. The destructive tests revealed types of flaws which were considered objectionable. These were shrink, pipe and porosity. The shrink area generally appeared at the upper third of the casting. The pipe or shrink was invariably surrounded by areas of microporosity and macroporosity. The presence of this porosity shrouded the recording of the exact shape of the shrink or pipe; however, this defect in itself was objectionable. Figure 17 is a recording of casting K76-10 which indicates by the white area a region of shrink and porosity at the top. This area can be seen in Figure 18, which was a 


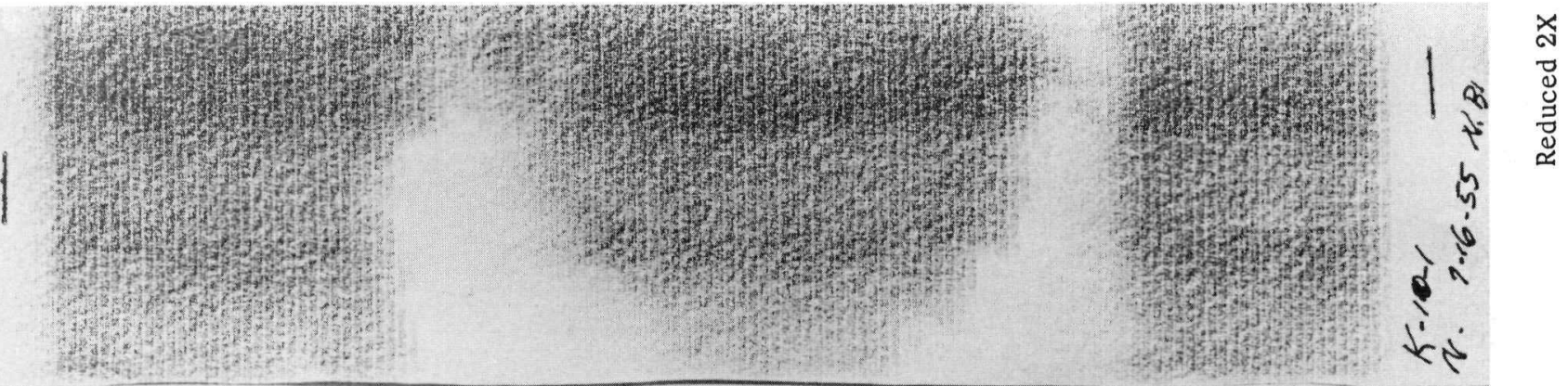

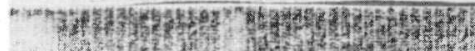

7.

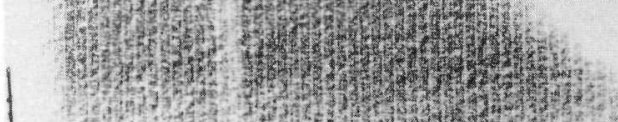

2.

7.

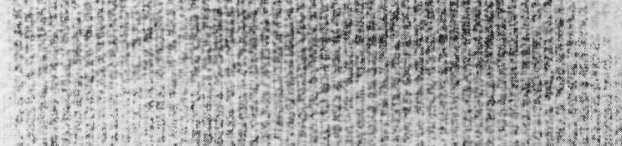

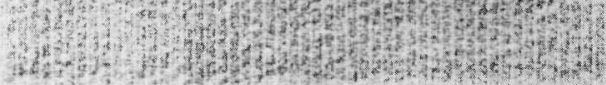
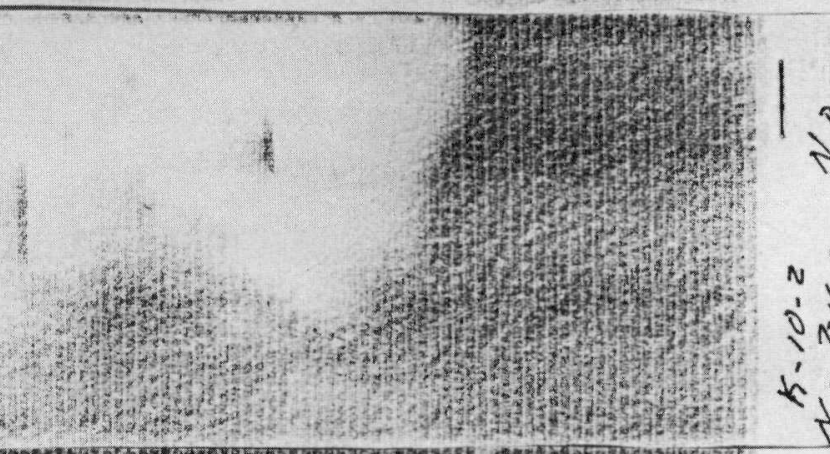

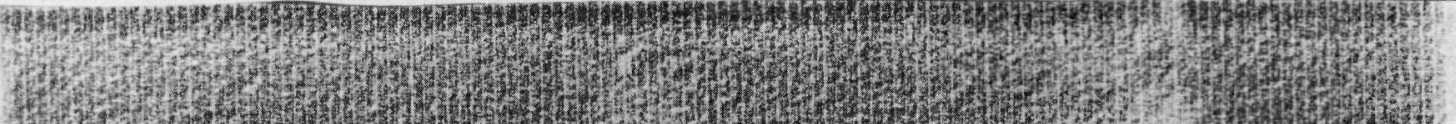

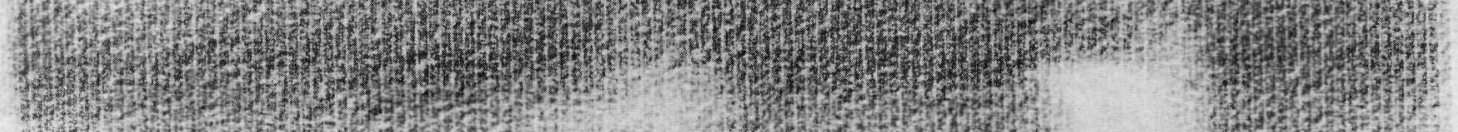

H.

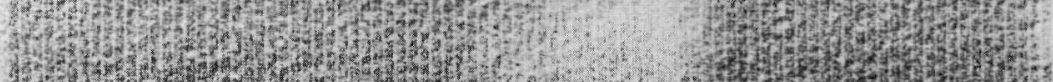

137

2.

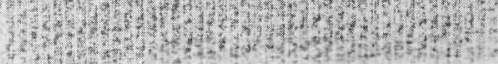

B.

1

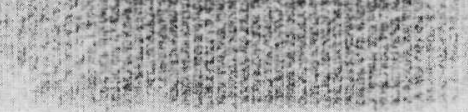

Mroray

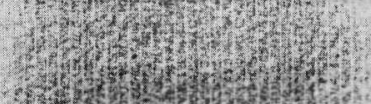

and

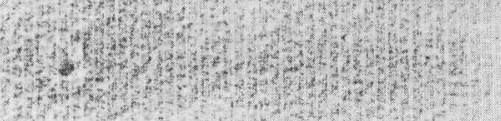

S.

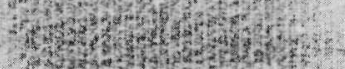

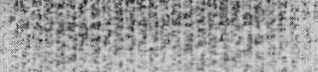

$3+2 y^{2}$

6
4
4

3) 1 (1)

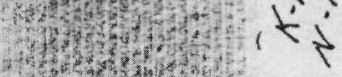

In

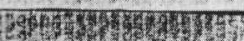

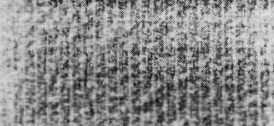

1.

is

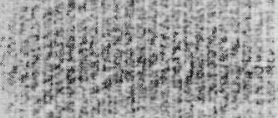

thet 1 and

2.

(4t act

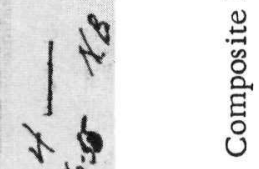

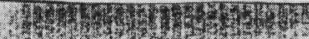

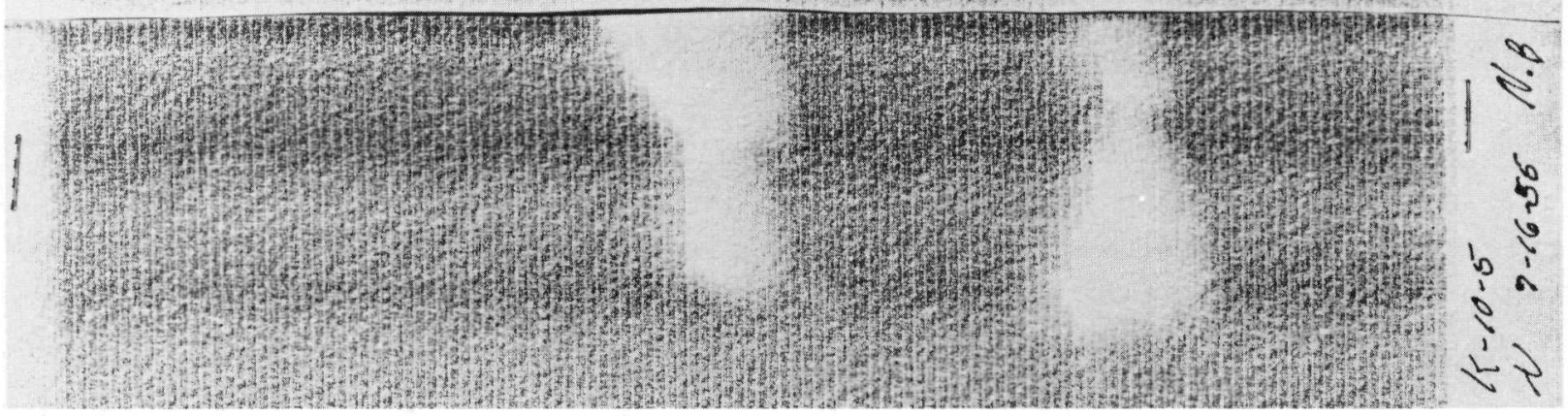



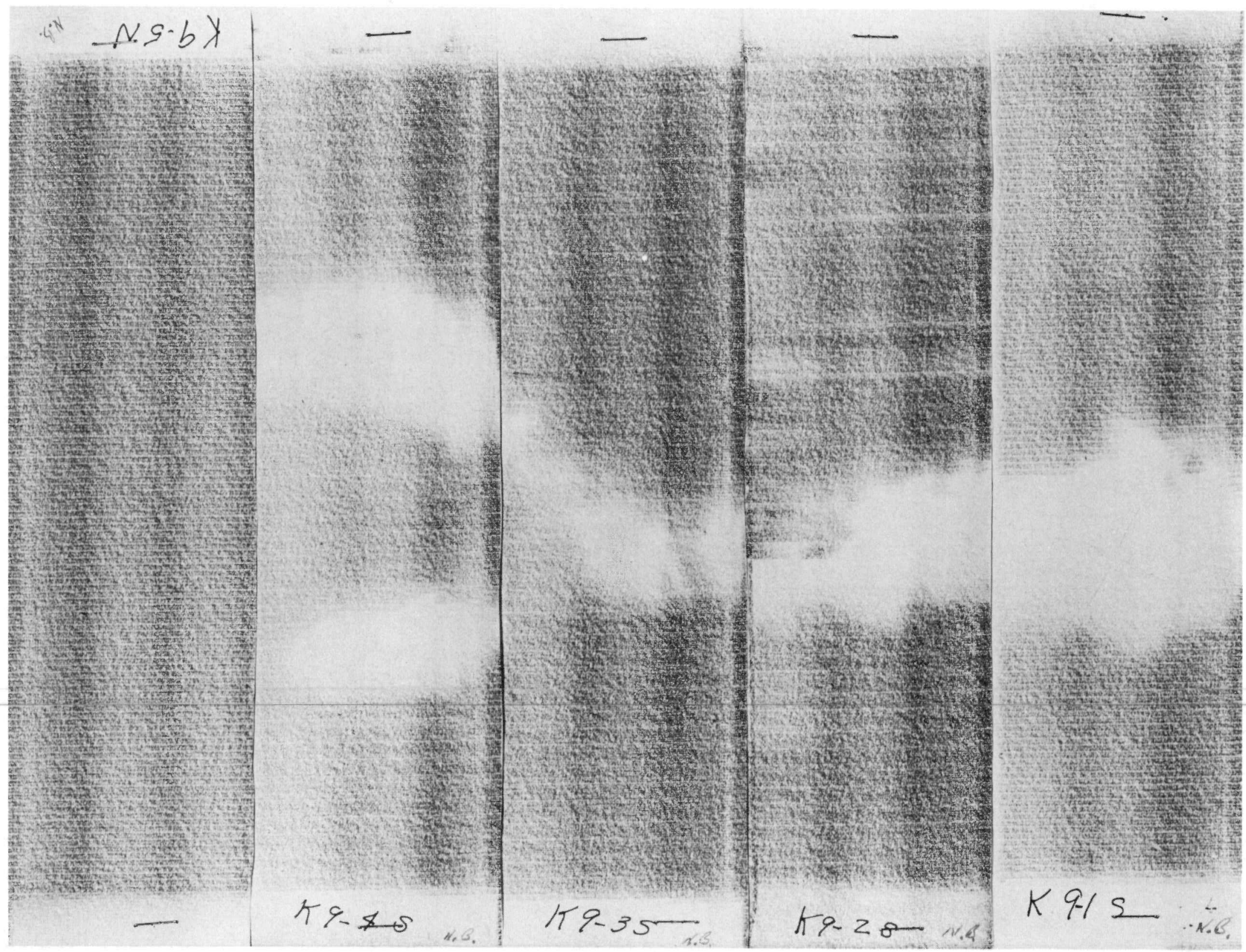

Reduced 20X 


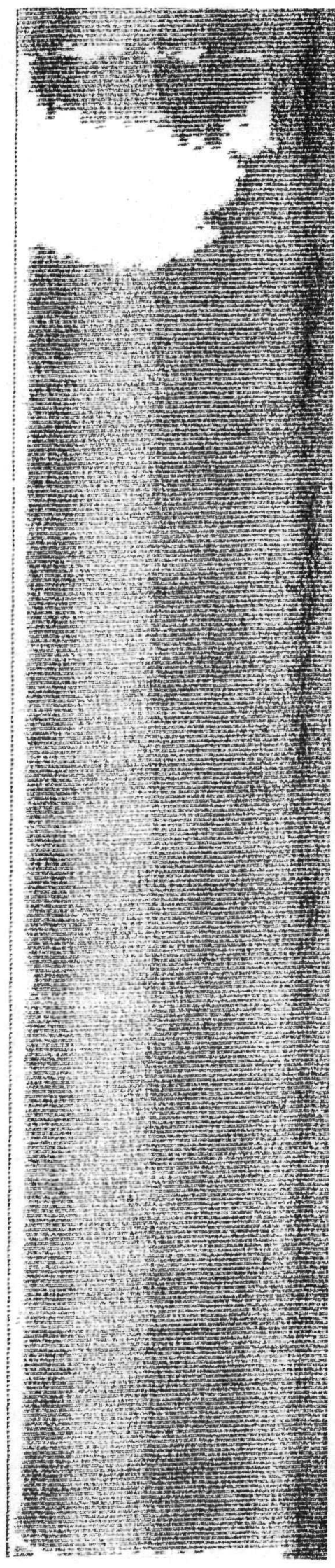

One Half Scale transverse cut of the section in question. The contour of the defect closely approximates that of the recording. This casting and its recording was established as a standard for the remainder of the development program and for the actual production items. Subsequent changes in casting technique were directed toward the isolation and reduction of the shrink area. For the fabrication of fuel elements a minimum length of $10 \frac{1}{2}$ inches of sound casting was required. In order to attain this, the mold was lengthened so as to allow a safe margin for shrink area which could be cut off, leaving the required length of sound casting.

A total of 329 EBWR uranium alloy cores were tested during the development program. A tabulation of the cores, the ingot and the particular mold used is listed in Table I. The mold which was selected for the fabrication of cores was the one which is referred to as "Eight cavity - eight core."

\section{ULTRASONIC TEST OF THE EBWR FUEL PLATES}

\section{Description of Element}

The EBWR flat-type fuel element measured 53 inches in length, $3 \frac{3}{4}$ inches in width and approximately $\mathrm{I} / 4$ inch thick. The plates had either a normal or an enriched uranium alloy core clad with approximately 20 mils of Zircaloy-2. The core was of uniform thickness and width with the exception of the last $2 \frac{1}{2}$ inches on each end where there is a gradual tapering from the full thickness to a sharp edge. The taper was not generally uniform, but was characterized by undulations. (8) (9)

\section{Test Procedure}

The fuel elements were placed lengthwise in the test tank on a special fixture which

Figure 17. Recording of Casting K76-10 Indicating Area of Shrink. 


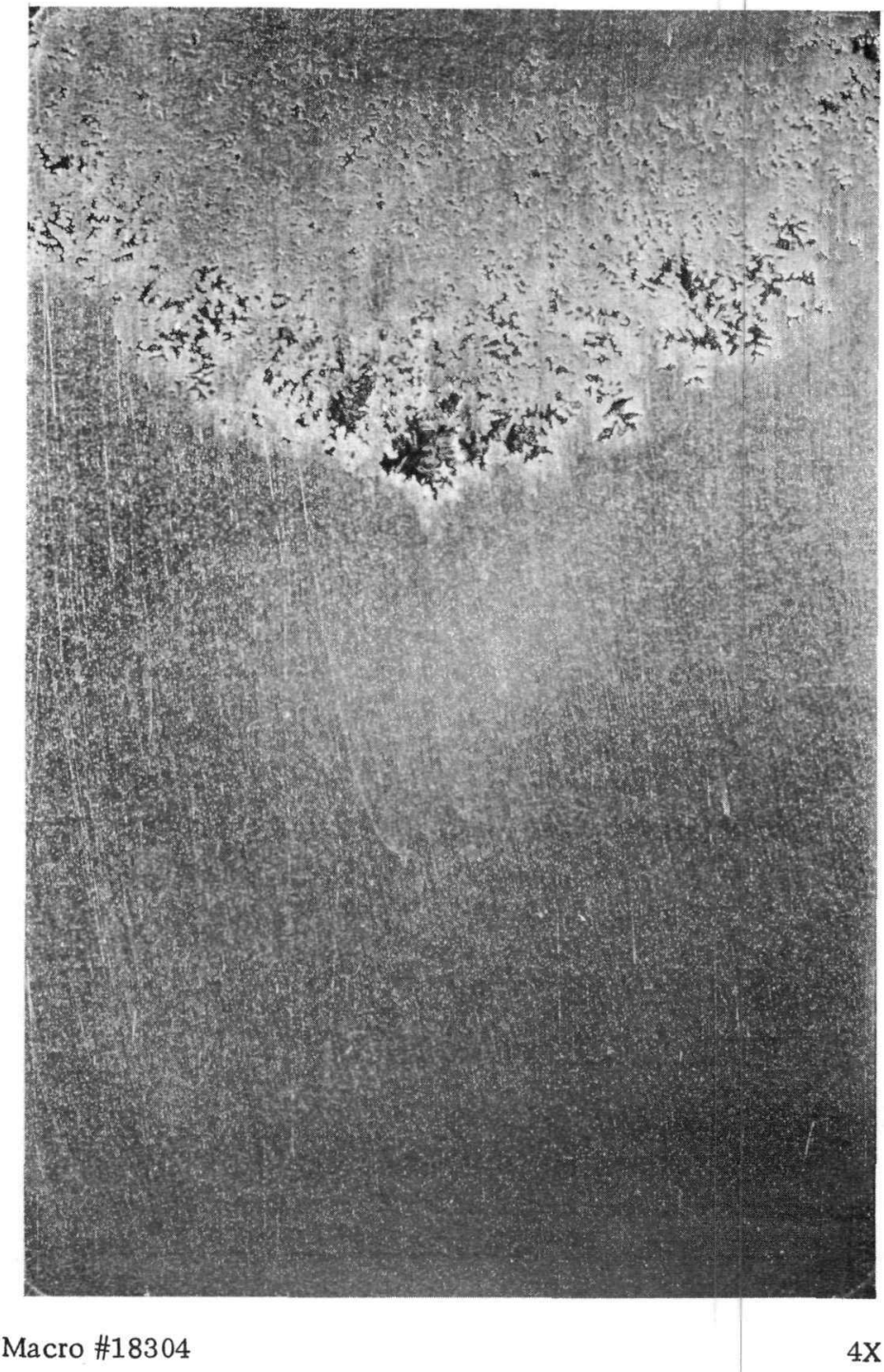

Figure 18. Cut-away section of casting K76-10 showing shrink area recorded in Figure 17.

supported the plate on edge. The transducer yoke straddled the plate and was positioned so that the transmitted ultrasonic beam maintained an angle of $90^{\circ} \pm 1 / 2^{\circ}$ to the surface of the plate. The horizontal motion of the carriage was set to 8 inches/minute, which would allow a $1 / 16$-inch scan overlap. The overlap assured that every successive sweep of the 5/64-inch diameter ultrasonic beam would completely inspect the fuel element. Several tests were made of sample plates which were then sectioned at selected areas and inspected for defects.

The presence of a nonbond area was discernible, as well as the presence of separations in the core material and in the cladding. By the application 
of a transmission technique any separation throughout the core cross section could be detected. Any type of separation was considered objectionable and any element indicating this effect was considered defective and not acceptable for installation in an EBWR subassembly. Successive destruction tests determined that with an ultrasonic beam aperture of $5 / 64$ inch, a nonbond area of $1 / 8$ square inch could be detected. As a means of demonstrating this resolution, a fuel plate was prepared which had simulated known size nonbonded areas. The simulated nonbonded areas were made by affixing acoustically absorbent material of known size on the surface of the plate. A recording of this sample plate can be seen in Figure 19. The white spots on the trace are the artificial defects.

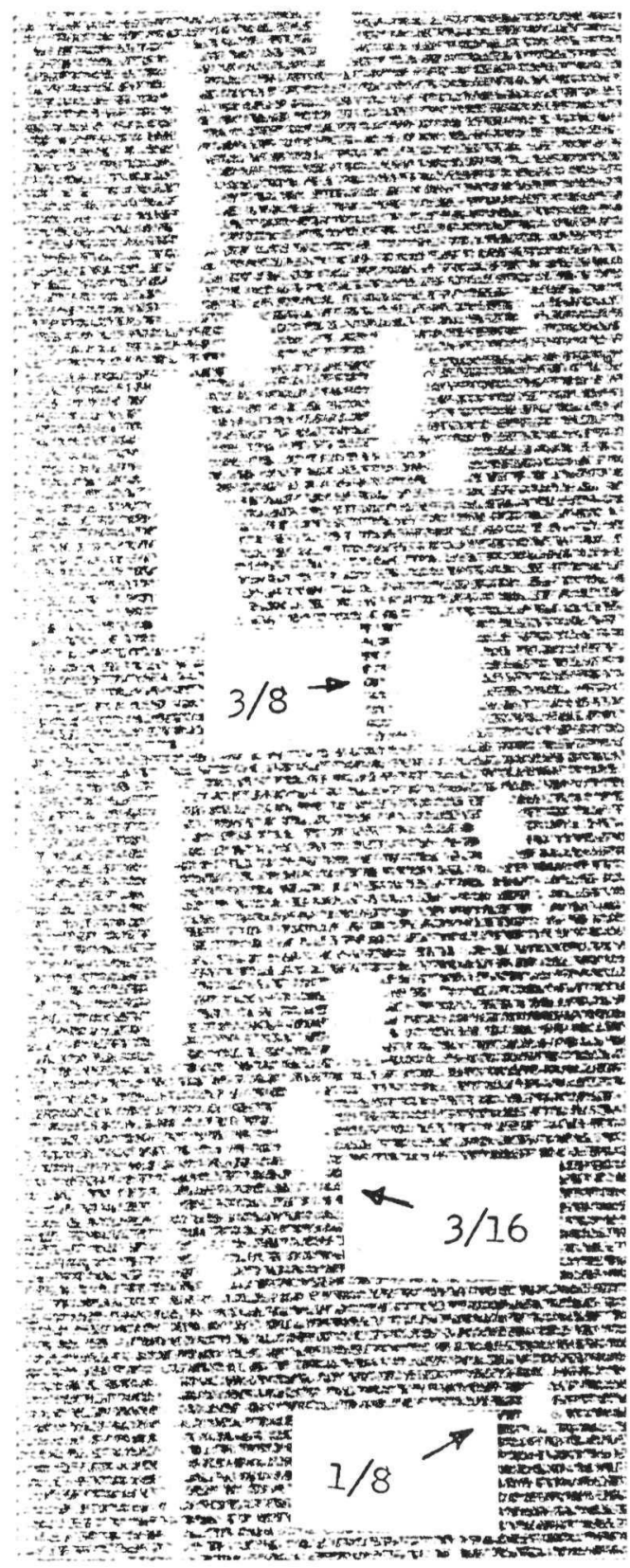

Macro \#21422
As stated, the core of the element was uniform in width and thickness, with the exception of the extreme ends which tapered from the full thickness to a sharp edge. This wedge proved to be an effective acoustic prism which refracted the transmitted energy to such a degree that identification of a nonbond in this area was inconclusive. Tensile tests were made of the bond layer over this wedge, which was found to have adequate bond strength. The difficulty was eliminated by repositioning the receiving transducer so that it was only $1 / 2$ inch from the surface of the plate. The size of the receiving crystal was changed from $1 / 2$-inch diameter to 1 -inch diameter. By doing so, the refracted beam could be received by the transducer. These modifications eliminated the effect noted and an accurate recording of the bond characteristics of these tapered ends could be determined.

In several fuel plates a small random defect was recorded. The size of the flaw was noted to be approximately $3 / 64 \mathrm{inch}$ in diameter

Figure 19. Recording of known defect plate used to determine resolution of equipment. 
and was isolated to particular plates. A destructive test of the area in question did not indicate the presence of an obvious nonbond or crack. Several of the se samples were subjected to an extended corrosion test and as a result of this it was observed that an inclusion in the core material had been "eaten" away. It was also noted that the inclusions recorded were those that were adjacent to the bond line. Due to the minute area presented, a tensile test of the bond layer directly over the inclusion was not attempted; however, it is speculated that the inclusion had some effect on the bond layer which was detected by the ultrasonic test see Figure 20.

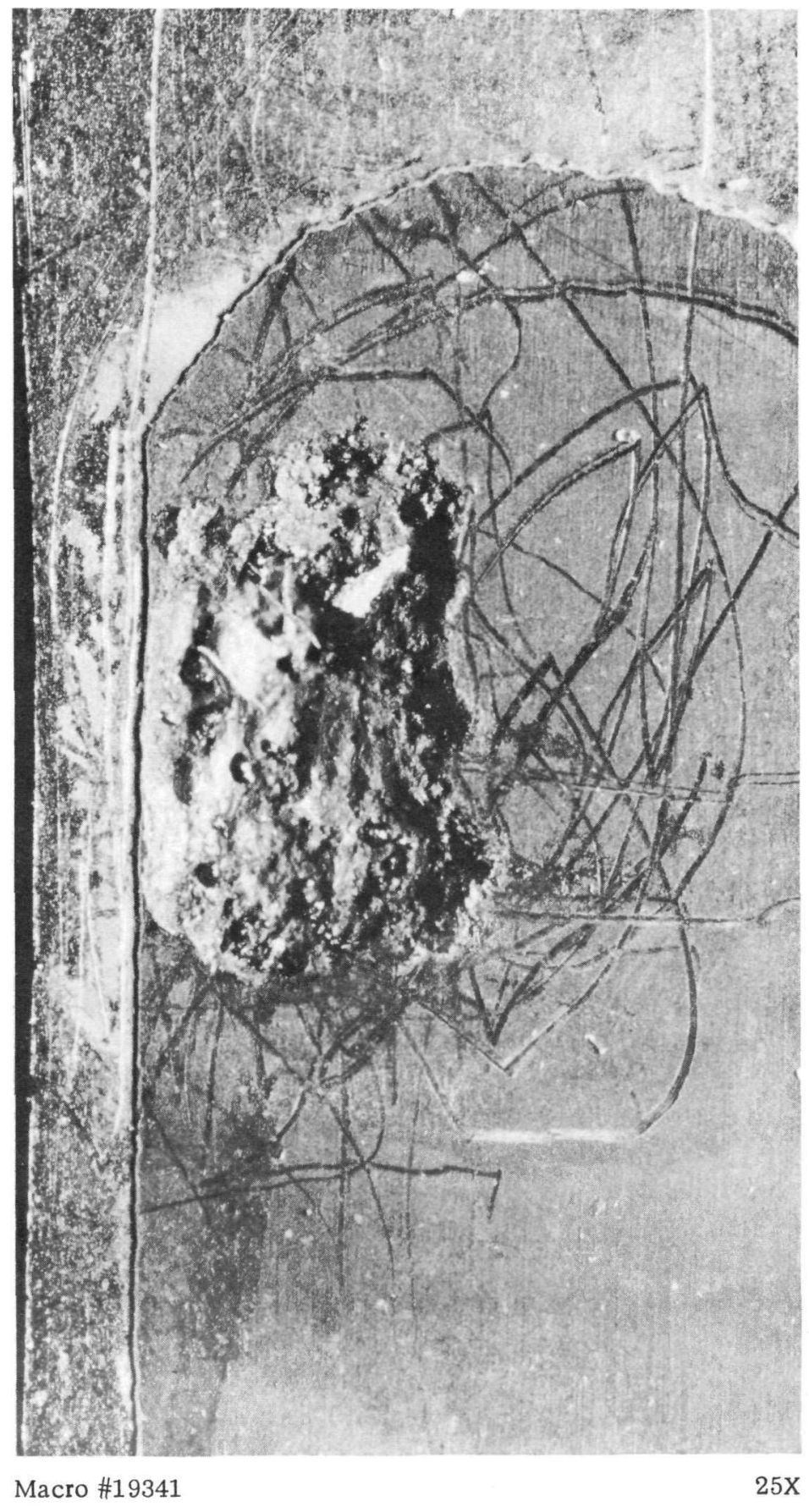

Figure 20. Photograph of etched-out inclusion in fuel plate which was detected ultrasonically. 
The presence of this inclusion and its effect on the bond layer was not considered to be of such magnitude as to adversely affect the integrity of the fuel element. The appearance of this type of flaw was therefore disregarded.

A representative nonbonded area detected and recorded can be seen in Figure 21. This is a section view showing a separation in the bond line which extends almost the half-width of the plate. Another type of separation can be seen in Figure 22. In this case the break occurred in the Zircaloy-Zircaloy cladding.

In the development of the ultrasonic nonbond test a total of 22 fuel plates were tested. A destructive test was made of every fuel element which indicated a discrepancy or recorded flaw. The plates were inspected before and after having been subjected to heat treatments, pickling and thermocycling. There was no conclusive evidence which indicated a bond failure of a once-established bonded element which had been processed by the above mentioned methods.

\section{ULTR ASONIC TEST OF FUEL ELEMENTS IN SUBASSEMBLIES}

An EBWR subassembly consists of six fuel plates spaced $7 / 16$ inches apart and spot welded to Zircaloy side plates. The selection of plate to be used in each subassembly was determined by core composition and compliance to the prescribed dimensional tolerances and results of the nondestructive tests.

Certain fuel plates, however, were inadvertently welded into subassemblies before having been inspected for nonbonding. In consideration of the effort involved in extracting the plates, the test was performed on the elements while still in the subassembly.

In order to perform the inspection a special two-arm probe was designed and fabricated. The dimension of the arm was made so that it would slide freely between the plates, yet restrict excessive lateral or torsional motions. Both arms were clamped at one end to a spacer block. The free end of each arm was equipped with a movable finger, the extremity of which housed an ultrasonic transducer. The crystals were matched 1/2-inch diameter barium titanate, ground to a natural resonating frequency of $5 \mathrm{Mc}$. The positioning and motion of the two fingers were controlled by cables which were fixed to a common level attached to the spacer block. The cables were guided in 1/16-inch slots milled in the edges of the arms. Activating the level would cause both fingers to transcribe an arc, the chord of which was equivalent to the width of the plate. 


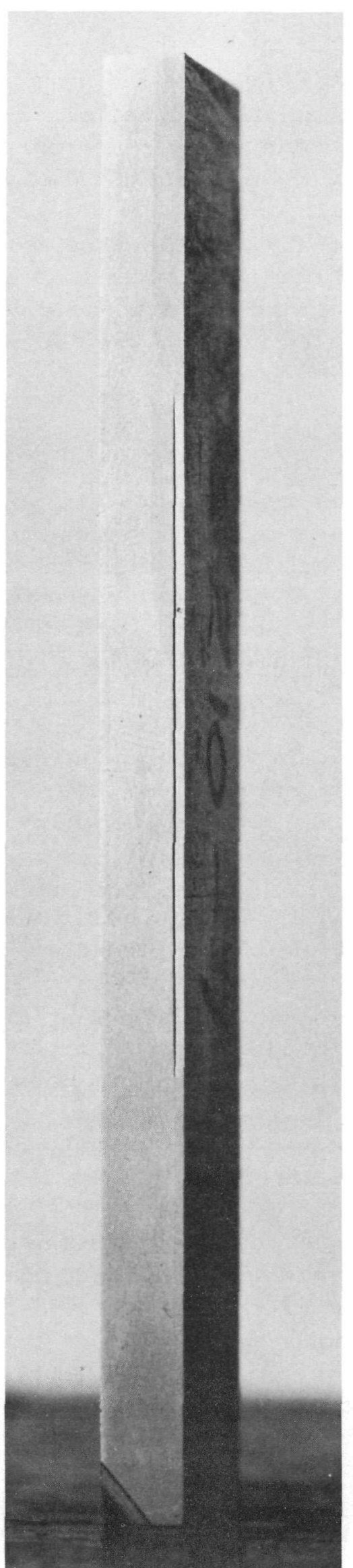

Figure 21. Core to Clad Nonbonded Area Detected in Fuel Plate.

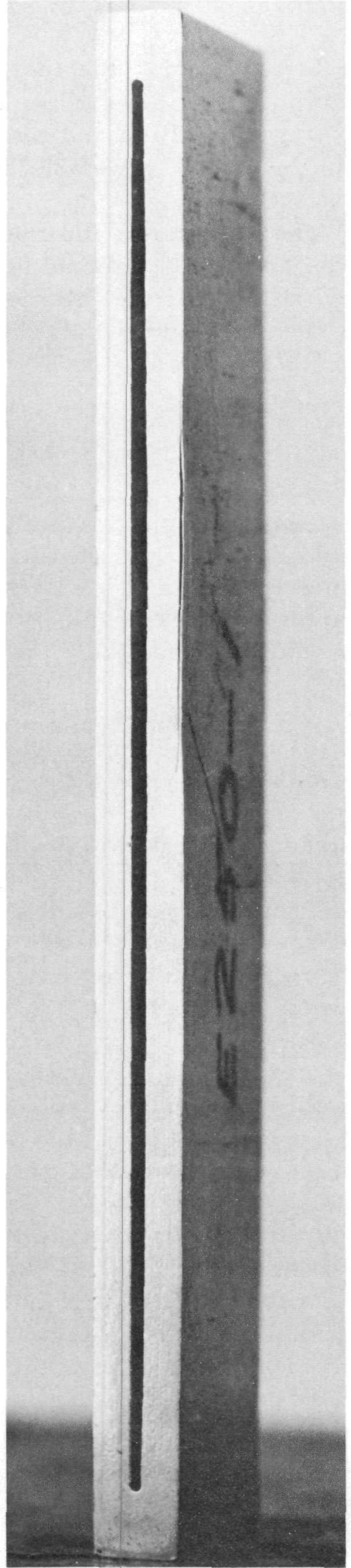

Figure 22. Nonbond Area in the ZircaloyZircaloy Inner Face. 
In performing the test, the probe was inserted into the assembly, one arm on either side of the plate which was to be inspected. By indexing the finger location and manually withdrawing the probe from the as sembly, the width as well as the breadth of the element could be inspected.

The ultrasonic and tank facilities of the scanner were used; however, the automatic recording system was omitted inasmuch as the test involved only eight fuel elements. A photograph of the probe and assembly can be seen in Figure 23. The probe inserted in a subassembly is shown in Figure 24.

\section{CONCLUSION}

The ultrasonic equipment which was designed for these tests was subjected to numerous calibration tests which demonstrated the reliability of the mechanical and electronic systems. At the maximum scanning rate the scanning and recording equipment maintained synchronization and performed repeated, faithful reproduction of ultrasonic images.

Known samples and defects were used as a basis of determining the resolution of the equipment. Destructive tests were frequently made in order to correlate flaws that were detected and recorded.

\section{(1) Ultrasonic Tests of Uranium Alloy Castings}

From tests conducted on 329 cores, it was determined that an ultrasonic inspection of the uranium castings could be performed which would provide reliable information as to the defects in the material. The defects which were isolated as being detrimental to the casting were piping, shrink and porosity. In addition to these, it was found that variations in structure, such as change in grain size, macro-inclusions, micro-inclusions and flaking, would also be detected.

(2) Ultrasonic Tests of the EBWR Fuel Plates

An ultrasonic transmission technique was utilized in the determination of nonbonding in the fuel plates. It was possible to accurately detect and record areas $1 / 8$ inch in diameter which were nonbonded. The separations noted were primarily on the bond layer; however, cracks in core cladding were also detected. Tests were made on plates before and after they had been thermocycled in autoclaves. There was no evidence which indicated a change in bond characteristics due to this procedure. 


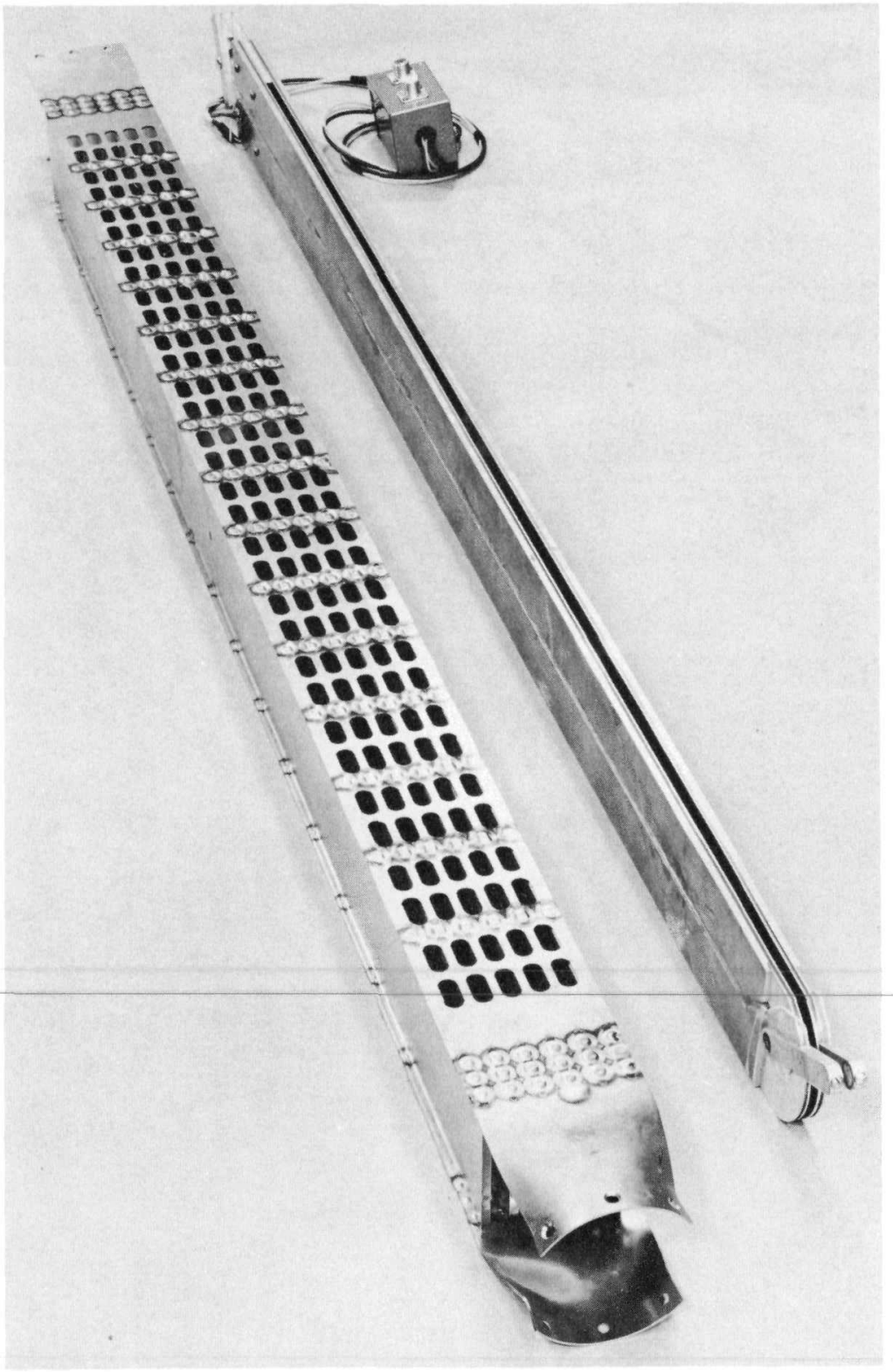

Figure 23. EBWR Subassembly and Ultrasonic Probe Designed to Test Fuel Plates While in Subassembly.

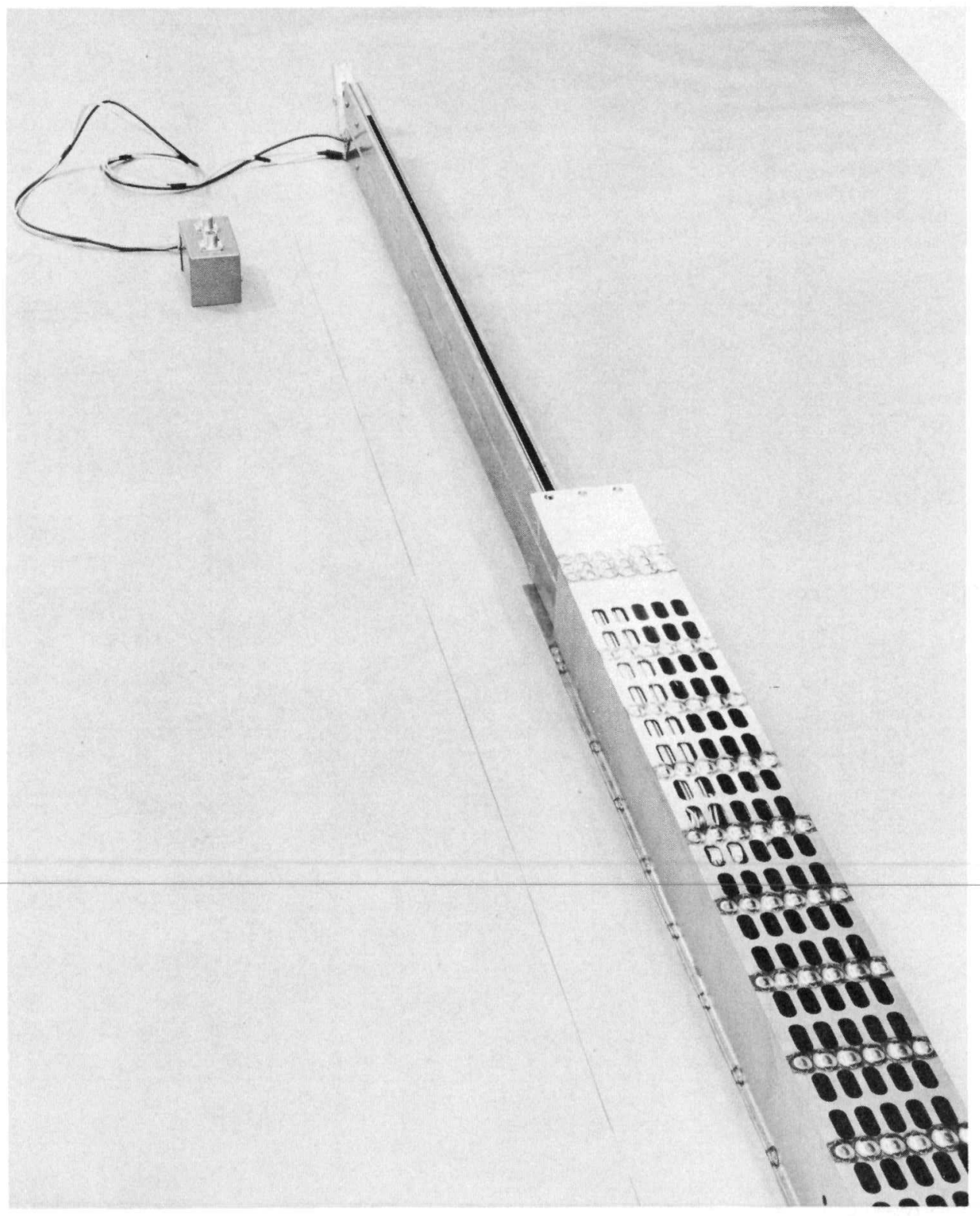

Figure 24. Photograph of Probe Inserted in Subassembly. 
(3) Ultrasonic Test of Fuel Elements in Subassemblies

A special two-arm probe was designed and fabricated to test fuel plates installed in subassemblies. A transmission technique was applied at an ultrasonic frequency of 5 megacycles. Eight fuel plates in six assemblies were tested with the probe. All plates were found to have adequate bonding.

\section{ACKNOWLEDGEMENT}

The authors wish to acknowledge the assistance of the foundry group of Argonne National Laboratory, who performed the destructive tests.

\section{REFERENCES}

1. Worlton, D. C. and Wood, E. C., "Preliminary Report on Ultrasonic Properties of Uranium," HW-26003 (October 27, 1952).

2. Blucke, W. L., "Transformation and Nonbond Tester for Flat Elements," DP-60 (Apri1, 1954).

3. McGonnagle, W. J. and Doe, W. B., "Eddy Current and Ultrasonic Testing of CP-6 Fuel Elements" ANL-5161 (December, 1953).

4. Richardson, E. G., "Ultrasonic Physics," Elsevier Publishing Company (1952).

5. Beck, W. N., "An Ultrasonic Scanning and Recording System," Journal of Nondestructive Testing, January-February, 1957.

6. Carson, N. J., Jr., and Macherey, R. E., "Development of Methods for Making and Casting Uranium-Rich Zirconium-Niobium Alloys," ANL-5627 (To be published).

7. Rooney, R. K., "The Influence of Metal Grain Structure on the Attenuation of an Ultrasonic Acoustic Wave," Calif. Inst. of Tech. Ph.D. Thesis, 1950.

8. Bean, C. H., Macherey, R. E. and Lindgren, J. R., "Roll Cladding Zirconium and Uranium Zirconium Niobium Alloys with Zircaloy-2 in Plate Type Fuel Elements," ANL-5628 (To be published).

9. Macherey, R. E., Bean, C. H., Lindgren, J. R. and Carson, N. J., Jr., "Manufacture of Fuel Plates for the Experimental Boiling Water Reactor," ANL-5629 (To be published). 
Table I

TABULATION OF CORES TESTED

\begin{tabular}{|c|c|c|}
\hline Mold & Ingot No. & Core Tested \\
\hline \multirow[t]{12}{*}{ Slab Mold - 32" } & $K-5$ & $-1-2-3$ \\
\hline & $K-6$ & $-1-2-3-4-5-6-7$ \\
\hline & $\mathrm{K}-7$ & $-1-2-3-4-5-6$ \\
\hline & $\mathrm{K}-9$ & $-1-2-3-4-5$ \\
\hline & $\mathrm{K}-10$ & $-1-2-3-4-5$ \\
\hline & $\mathrm{K}-13$ & $-1-2-3-4-5-6-7$ \\
\hline & $\mathrm{K}-14$ & $-1-2-3-4$ \\
\hline & $\mathrm{K}-16$ & $-1-2-3-4-5$ \\
\hline & $\mathrm{K}-15$ & $-1-2-3-4-5-6-7$ \\
\hline & $\mathrm{K}-20$ & $-1-2-3-4-5-6-7$ \\
\hline & $\mathrm{K}-19$ & $-1-2-3-4-5-6-7$ \\
\hline & $\mathrm{K}-17$ & $-2-3-4-5-6-7-8$ \\
\hline \multirow[t]{8}{*}{ Three cavity-three core } & $\mathrm{K}-22$ & $A-B-C$ \\
\hline & $\mathrm{K}-25$ & $A-B-C$ \\
\hline & $\mathrm{K}-27$ & $A-B-C$ \\
\hline & $K-23$ & $A-B-C$ \\
\hline & $K-26$ & $A-B-C$ \\
\hline & $\mathrm{K}-29$ & $A-B-C$ \\
\hline & $\mathrm{K}-31$ & $A-B-C$ \\
\hline & $\mathrm{K}-34$ & $A-B-C$ \\
\hline \multirow[t]{9}{*}{ Slab Mold - 35" } & $K-56$ & $-1-2-3-4-5-6-7-8$ \\
\hline & $K-59$ & $-2-3-4-5-6-7-8-9$ \\
\hline & $\mathrm{K}-63$ & $-1-2-3-4-5-6-7-8$ \\
\hline & $K-68$ & $-1-2-3-4-5-6-7-8$ \\
\hline & $\mathrm{K}-71$ & $-1-2-3-4-5-6-7$ \\
\hline & $\mathrm{K}-73$ & $-1-2-3-4-5-6-7-8$ \\
\hline & $\mathrm{K}-74$ & $-1-2-3-4-5-6$ \\
\hline & $\mathrm{K}-77$ & $-1-2-3-4-5-6-7-8$ \\
\hline & $\mathrm{K}-78$ & $-1-2-3-4-5-6-7-8$ \\
\hline \multirow[t]{10}{*}{ Three cavity-six core } & $K-36$ & $\mathrm{Al}-\mathrm{A} 2-\mathrm{Bl}-\mathrm{B} 2-\mathrm{Cl}-\mathrm{C} 2$ \\
\hline & $\mathrm{K}-37$ & Al \\
\hline & $\mathrm{K}-41$ & $\mathrm{~A} 1-\mathrm{A} 2-\mathrm{B} 1-\mathrm{B} 2-\mathrm{C} 1-\mathrm{C} 2$ \\
\hline & $\mathrm{K}-46$ & $\mathrm{~A} 1-\mathrm{A} 2-\mathrm{B} 1-\mathrm{B} 2-\mathrm{C} 1-\mathrm{C} 2$ \\
\hline & $\begin{array}{l}\mathrm{K}-48 \\
\mathrm{~K}-53\end{array}$ & $\begin{array}{l}\mathrm{A} 1-\mathrm{A} 2-\mathrm{B} 1-\mathrm{B} 2-\mathrm{Cl}-\mathrm{C} 2 \\
\mathrm{~A} 1-\mathrm{B} 1-\mathrm{C} 1\end{array}$ \\
\hline & $\mathrm{K}-64$ & $\mathrm{Al}-\mathrm{A} 2-\mathrm{Bl}-\mathrm{B} 2-\mathrm{Cl}-\mathrm{C} 2$ \\
\hline & $K-57$ & $\mathrm{Al}-\mathrm{A} 2-\mathrm{B} 1-\mathrm{B} 2-\mathrm{Cl}-\mathrm{C} 2$ \\
\hline & $K-60$ & $\mathrm{~A} 2-\mathrm{B} 2$ \\
\hline & $K-69$ & $\mathrm{~A} 1-\mathrm{A} 2-\mathrm{B} 1-\mathrm{B} 2-\mathrm{C} 1-\mathrm{C} 2$ \\
\hline & $\mathrm{K}-33$ & $\mathrm{Al}-\mathrm{B} 2-\mathrm{Cl}$ \\
\hline \multirow[t]{9}{*}{ Eight cavity-eight core } & $\mathrm{K}-39$ & $-1-2-6-7$ \\
\hline & $\mathrm{K}-44$ & $-1-2-3-4-5-6-7-8$ \\
\hline & $\mathrm{K}-47$ & $-2-3-5-$ \\
\hline & $K-58$ & $-1-2-5-7$ \\
\hline & $\mathrm{K}-62$ & $-1-3-4-5-6-7-8$ \\
\hline & $\mathrm{K}-67$ & $-1-2-3-4-5-6-7-8$ \\
\hline & $K-70$ & $-1-2-3-4-5-6-7-8$ \\
\hline & $\mathrm{K}-72$ & $-1-2-3-4-7$ \\
\hline & $K-54$ & $-1-2-3-4-5-6-7-8$ \\
\hline \multirow[t]{2}{*}{ Ten cavity-ten core } & $K-75$ & $-2-3-4-5-6-7-8$ \\
\hline & $K-76$ & $-2-3-4$ \\
\hline \multirow[t]{7}{*}{ Slab Mold - 34" } & $\mathrm{K}-43$ & $-1-2-3-4-5-6-7$ \\
\hline & $K-45$ & $-1-2-3-4-5-6-7$ \\
\hline & $K-49$ & $-1-2-3-4-5-6-7$ \\
\hline & $K-66$ & $-1-2-3-4-5-6-7$ \\
\hline & $K-51$ & $-1-2-3-4-5-6-7-8$ \\
\hline & $K-52$ & $-1-2-3-4-5-6-7$ \\
\hline & $\mathrm{K}-61$ & $-1-2-3-4-5-6-7$ \\
\hline
\end{tabular}

